\title{
Prediction of the fouling penalty on the tidal turbine performance and development of its mitigation measures
}

Soonseok Song, Yigit Kemal Demirel, Mehmet Atlar, Weichao Shi*

Department of Naval Architecture, Ocean and Marine Engineering, University of Strathclyde, 100 Montrose Street, Glasgow G4 0LZ

Corresponding Author

Weichao Shi, Weichao.shi@strath.ac.uk

Department of Naval Architecture, Ocean \& Marine Engineering, University of Strathclyde

Henry Dyer Building, 100 Montrose Street,

Glasgow G4 0LZ, U.K.

Tel: 01415745349 


\begin{abstract}
The power coefficient for a horizontal axis tidal turbine is the determinant factor for the efficiency of a tidal energy system. To guarantee a highly efficient tidal turbine operating in the real sea environment for an enduring long period is of critical importance to the power production and hence the cost of energy. However, this performance is under the threat of marine biofouling and the biofouling effect on tidal turbine systems are barely known neither quantified. This paper focuses on the study of the roughness effect due to biofouling on the performance of a tidal turbine. A Reynolds Averaged Navier-Stokes model based Computational Fluid Dynamics (CFD) was developed to predict the effect of biofouling on a full-scale turbine. A roughness modelling that involves modified wall-functions in the CFD model was used representing the surface roughness caused by barnacle fouling. The simulations were conducted under different fouling scenarios for a range of tip speed ratios (TSR). The surface fouling resulted in up to $13 \%$ decrease in the power coefficient at the designed operating condition. The effect proved to be even more severe at higher TSRs, bringing narrower operating range of TSRs. The results also suggest that by lowering the operating TSRs for fouled turbines the fouling effect on efficiency losses can be minimised to ensure efficient operation between maintenances.
\end{abstract}

Keywords: biofouling; tidal turbine; roughness effect; computational fluid dynamics (CFD) 


\section{Introduction}

Tidal energy is an attractive form of marine renewable energy, which is reliable, predictable and richly distributed along the coastal regions [1-3]. Accordingly, there have been efforts for the developments of horizontal axis tidal turbines (HATT) over the last 20 years, and now it reached the stage of commercialisation.

The power converting efficiency of HATT is mainly quantified by the power coefficient, $C_{P}$ (Equation 8), which varies mainly with the operating conditions of the turbine. Therefore, understanding the behaviours of $C_{P}$ for a tidal turbine in the real sea is particularly important to maintain its best performance in operation. Amongst many threats, biofouling accumulation caused by marine creatures has a profound impact on the Levelised Cost of Electricity, LCOE, due to its impact on the maintenance schedule of turbine blades, the power output, and the structural integrity. It can be seen first in Figure 1, which demonstrates the marine fouling in the latest tidal turbine developed by NOVA Innovation. Moreover, the progress of fouling is developed on the tidal turbine blades with a staggering rate, which can be seen in Figure 2 from the Race Rocks Tidal Power Demonstration Project just 8 months after the turbine has been deployed into the sea. Whereas tidal energy system is supposed to be able to operate for 20-25 years' time. And it is now slowly getting the attention of the industrial leaders in the tidal energy industry. Currently, there is no clear solution. This is mainly because tidal energy technology is mainly inherited from the wind energy industry. The core technologies like turbine design, manufacturing, drive train, control as well as power take-off system are transferred from wind energy, in which marine fouling has never been an issue. But this is no longer the case for marine turbines. In this context, it is of great importance to understand the effect of biofouling on tidal turbine performance.

The accumulation of microorganisms, plants, algae, or animals on the surfaces of submerged, or semi-submerged, natural or artificial objects is termed marine biofouling [4]. Biofouling process often begins with the production of microfouling organisms. Where the conditions are right, bacteria such as Thiobacilli, and/or other microorganisms quickly colonise any substrate placed in seawater [5]. They form a sticky coating commonly referred to as a biofilm. The accumulation of biofilms does not only bring the difficulties for subsea operators but also provide both a food source and a convenient interface to which the larger organisms, the macrofouling, can adhere [6]. Fouling caused by large organisms, such as oysters, mussels, barnacles, seaweed and other organisms, is referred to as macrofouling. Macrofouling 
organisms can significantly affect the marine renewable energy converters, by causing obstructions in the device and increasing the weight and drag. Accordingly, large economic costs follow due to impaired equipment performance and the life span [6].

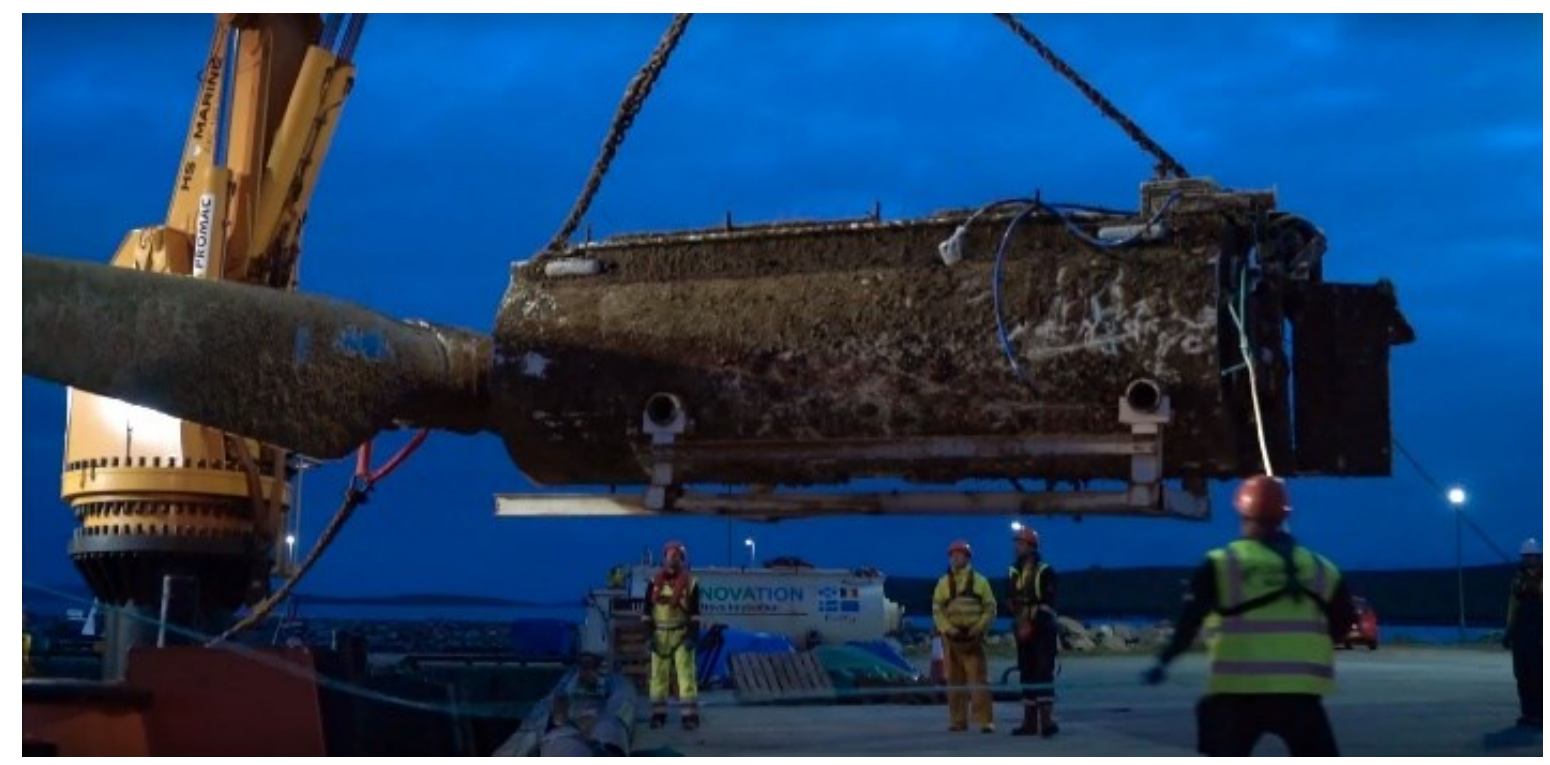

Figure 1 Fouled turbine by NOVA Innovation

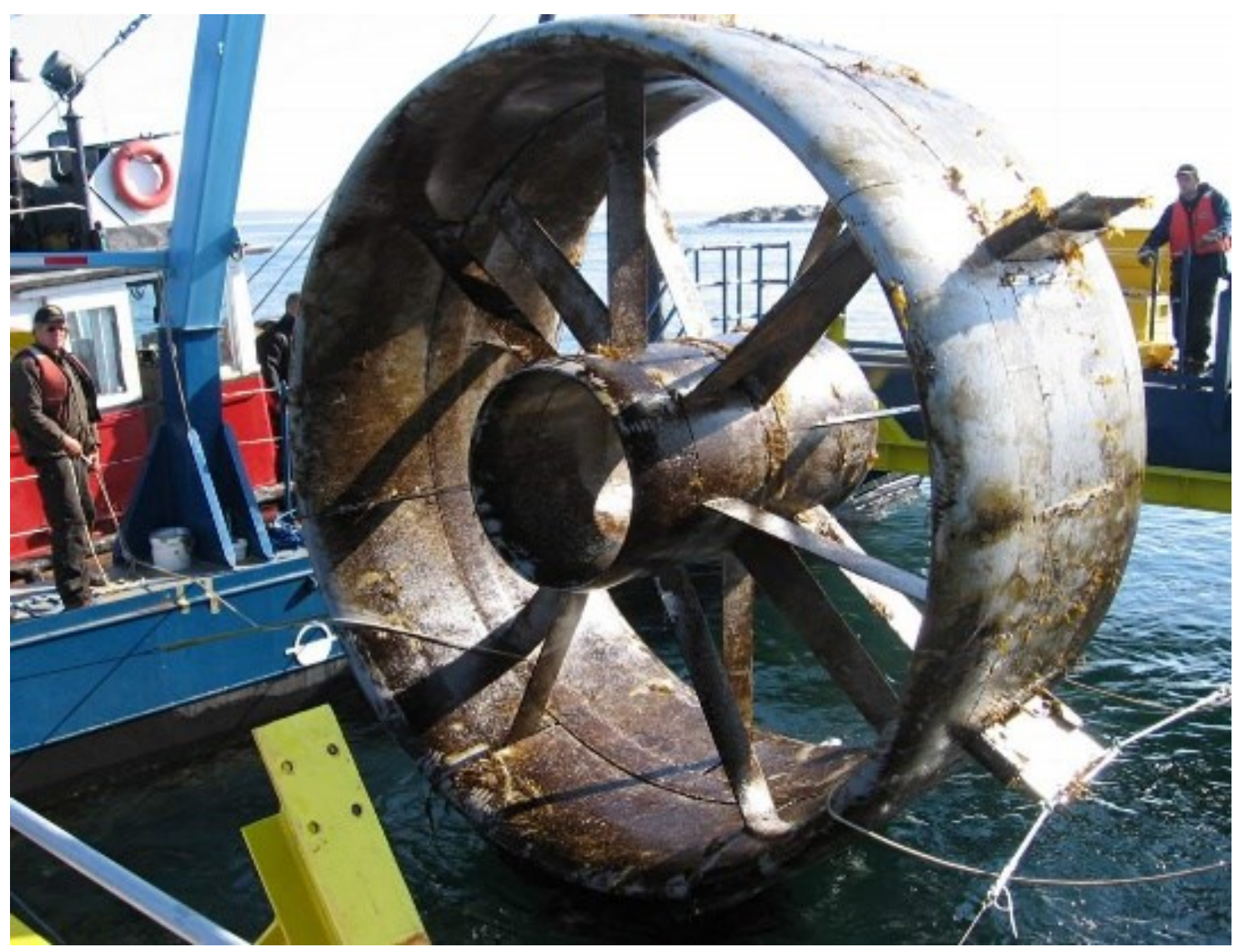

Figure 2 Fouling after 6 months (Clean Current Tidal Power Demonstration Project) 
Fraenkel [7] and $\mathrm{Ng}$ et al. [8] identified the potential performance issues for marine turbines arising from the roughening of the turbine blades caused by the impact, cavitation or scour due to particulates, and the biofouling on the blade surface. But there have been only a few studies devoted to exploring the effect of surface roughness or fouling on marine turbines performances.

Orme et al. [9] investigated the potential effects of barnacles on the lift and drag coefficients for an aerofoil using a wind tunnel. The aerofoil was covered with idealised barnacles of different sizes and coverage densities, and they found decreased lift to drag ratio due to the idealised barnacles. Batten et al. [10] studied the potential effects of increased blade roughness due to fouling using a numerical model based on blade element momentum (BEM) theory. They used a larger drag coefficient $C_{D}$ in the numerical model for the fouled cases but the lift coefficient $C_{L}$ was not altered in the numerical model. The numerical model predicted $6-8 \%$ decrease in power coefficient $C_{P}$. Walker et al. [11] conducted experimental and numerical studies to examine the effect of blade roughness and fouling on marine current turbine performance. They used a towing tank to test a model rotor in different surface conditions and a numerical BEM model was also developed altering the lift and drag coefficient according to the surface conditions. Both of their numerical and experimental results showed similar results suggesting that up to $19 \%$ of power coefficient $C_{P}$ can be reduced due to the surface roughness.

Although these studies clearly demonstrate the critical impact of biofouling on tidal turbine performances, they are still limited by several factors. First, it is questionable if the modelscale experiments can represent the hydrodynamic behaviour of the real tidal turbines. This is owing to the unique feature of the roughness effect in scaling. That is, the size of surface roughness cannot be scaled proportionally to the model size, as argued by Franzini [12]. In terms of the numerical BEM models, the roughness effect on the blades was only considered as the altered lift and drag coefficients of the blades rather than solving the fluid field around the turbine, e.g. the pressure field around the blades, which can bring significant differences.

In the field of naval architecture, CFD simulations have been actively used to predict the roughness effect while avoiding the above-mentioned difficulties. Demirel et al. [13] used a roughness modelling in CFD, which involves modifications of the wall-functions in the CFD models (i.e. modified wall-function approach) to represent the rough surfaces of marine coatings and biofouling. In CFD simulations, the distribution of the local friction velocity, $u_{\tau}$, is dynamically computed for each discretized cell, and therefore the dynamically varying 
roughness Reynolds number, $k^{+}$, and corresponding roughness function, $\Delta U^{+}$, can be taken into account in the computation, and the roughness effect in the flow can be precisely predicted including the pressure field around the body.

Recently, there have been increasing number of studies using the modified wall-function approach to predict the roughness effect of biofouling in ship resistance [14-16], propeller performance [17, 18], and ship self-propulsion characteristics [19]. Recently, Song et al. [20, 21] extended the validation of the modified wall-function approach by comparing the CFD simulation with the result of a towing test of Song et al. [22].

To the best of the authors' knowledge, there exists no specific study to investigate the effect of biofouling on a full-scale tidal turbine using CFD. Therefore, the aim of this study is to fill this gap by developing a CFD model to simulate the effect of biofouling on the tidal turbine performances. The main advantage of the proposed approach is that the CFD model enables an extensive analysis on the hydrodynamic details of the turbulent flow over the rough surface of a full-scale tidal turbine in a fully non-linear way, which is not possible using experimental or theoretical methods [9-11], as discussed earlier.

In this study, a previously developed CFD approach was applied, for approximating the surface roughness due to barnacle fouling, in order to predict the effects on the HATT performances. Full-scale CFD simulations of the HATT in different fouling conditions were conducted at the tip speed ratios (TSR), ranging from 1 to 8. Finally, the impact of barnacle fouling on the power coefficients and thrust coefficients were examined. 


\section{Numerical modelling}

\subsection{Roughness function}

The surface roughness increases the turbulence. Accordingly, the turbulent stress, wall shear stress and finally the skin friction increases. The roughness effect can also be observed in the velocity profile in the log-law region. Clauser [23] showed that the roughness effect results in a downward shift in the velocity profile in the log-law region. This downward shift is termed as the 'Roughness Function', $\Delta U^{+}$. The non-dimensional velocity profile in the log-law region for a rough surface is given as

$$
U^{+}=\frac{1}{\kappa} \ln y^{+}+B-\Delta U^{+}
$$

The roughness function, $\Delta U^{+}$can be expressed as a function of the roughness Reynolds number, $k^{+}$, defined as

$$
k^{+}=\frac{k U_{\tau}}{v}
$$

It should be borne in mind that $\Delta U^{+}$simply vanishes in the case of a smooth condition.

Demirel et al. [24] proposed an experimental approach to determine the roughness functions of barnacle fouling. The study involves an extensive series of towing test of flat plates covered with artificial barnacle patches. Different sizes of real barnacles, categorised as small, medium and big regarding their size, were 3D scanned and printed into artificial barnacle tiles. The tiles then glued onto the flat plates by differing the coverage and the plates were towed at a range of speeds. Figure 3 shows the geometry of the 3D scanned barnacles and the barnacle patches glued on the plate.

From the analysis of the experimental results, they found that the roughness function behaviours of the barnacles follow the roughness function model of Grigson [25] given as,

$$
\Delta U^{+}=\frac{1}{\kappa} \ln \left(1+k^{+}\right)
$$

Table 1 compares the roughness length scales for the fouling conditions of different barnacle sizes and coverage densities and Figure 4 shows the roughness functions obtained from the experiment and the roughness function calculated using Equation (3). 
Recently, Song et al. [16] employed this roughness function into the wall-function in the CFD model and conducted model-scale flat plate simulations. The results were compared against the experimental result of Demirel et al [24] and showed an excellent agreement. In this study, the same modified wall-function approach as Song et al. [16] was used to simulate the surface roughness of barnacles of varying sizes and coverages.
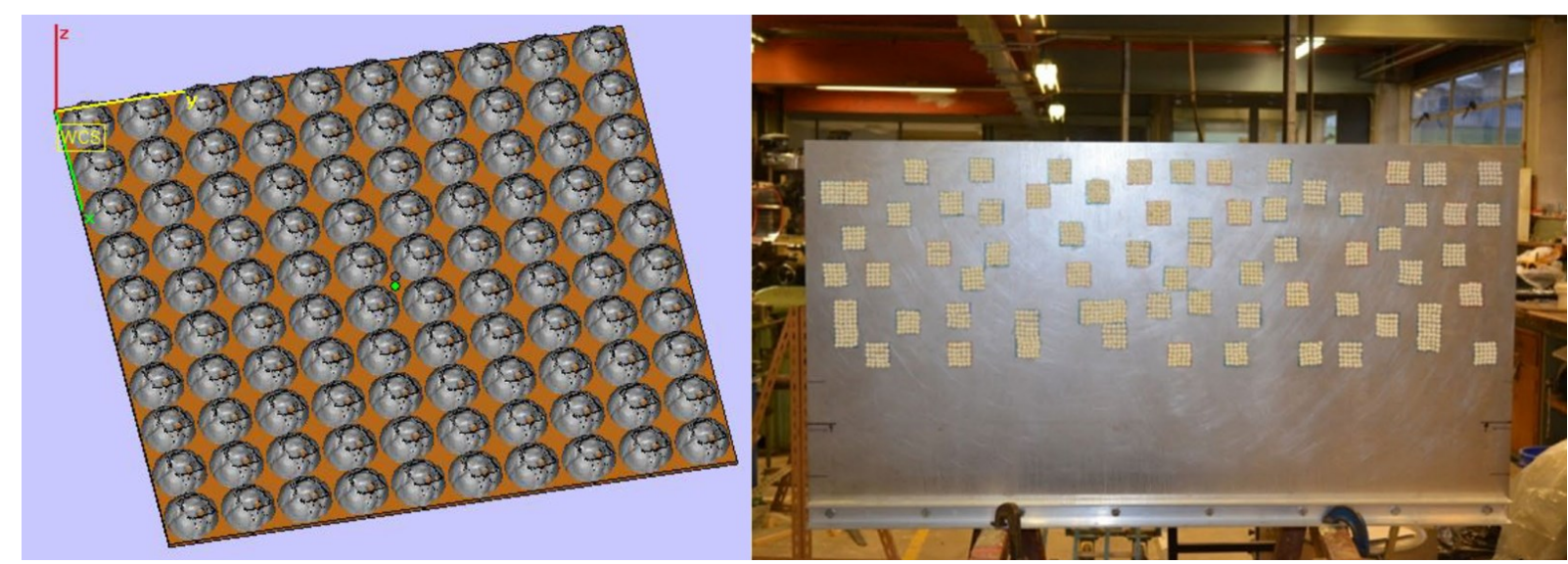

Figure 3 Digitised barnacle geometry (left) and the flat plate covered with the barnacle patches (right), adapted from Demirel et al. [24]

Table 1 Roughness length scales of the fouling conditions, adapted from Demirel et al. [24]

\begin{tabular}{lllll}
\hline $\begin{array}{l}\text { Surface } \\
\text { condition }\end{array}$ & Barnacle type & $\begin{array}{l}\text { Surface } \\
\text { coverage }(\%)\end{array}$ & $\begin{array}{l}\text { Barnacle } \\
\text { height } \\
h(\mathrm{~mm})\end{array}$ & $\begin{array}{l}\text { Representative sand- } \\
\text { grain roughness height } \\
k_{G}(\mu \mathrm{m})\end{array}$ \\
\hline B10\% & Big & $10 \%$ & 5 & 174 \\
$\mathrm{~B} 20 \%$ & Big & $20 \%$ & 5 & 489 \\
M10\% & Medium & $10 \%$ & 2.5 & 84 \\
M20\% & Medium & $20 \%$ & 2.5 & 165 \\
M40\% & Medium & $40 \%$ & 2.5 & 388 \\
M50\% & Medium & $50 \%$ & 2.5 & 460 \\
S10\% & Small & $10 \%$ & 1.25 & 24 \\
S20\% & Small & $20 \%$ & 1.25 & 63 \\
S40\% & Small & $40 \%$ & 1.25 & 149 \\
S50\% & Small & $50 \%$ & 1.25 & 194 \\
\hline
\end{tabular}




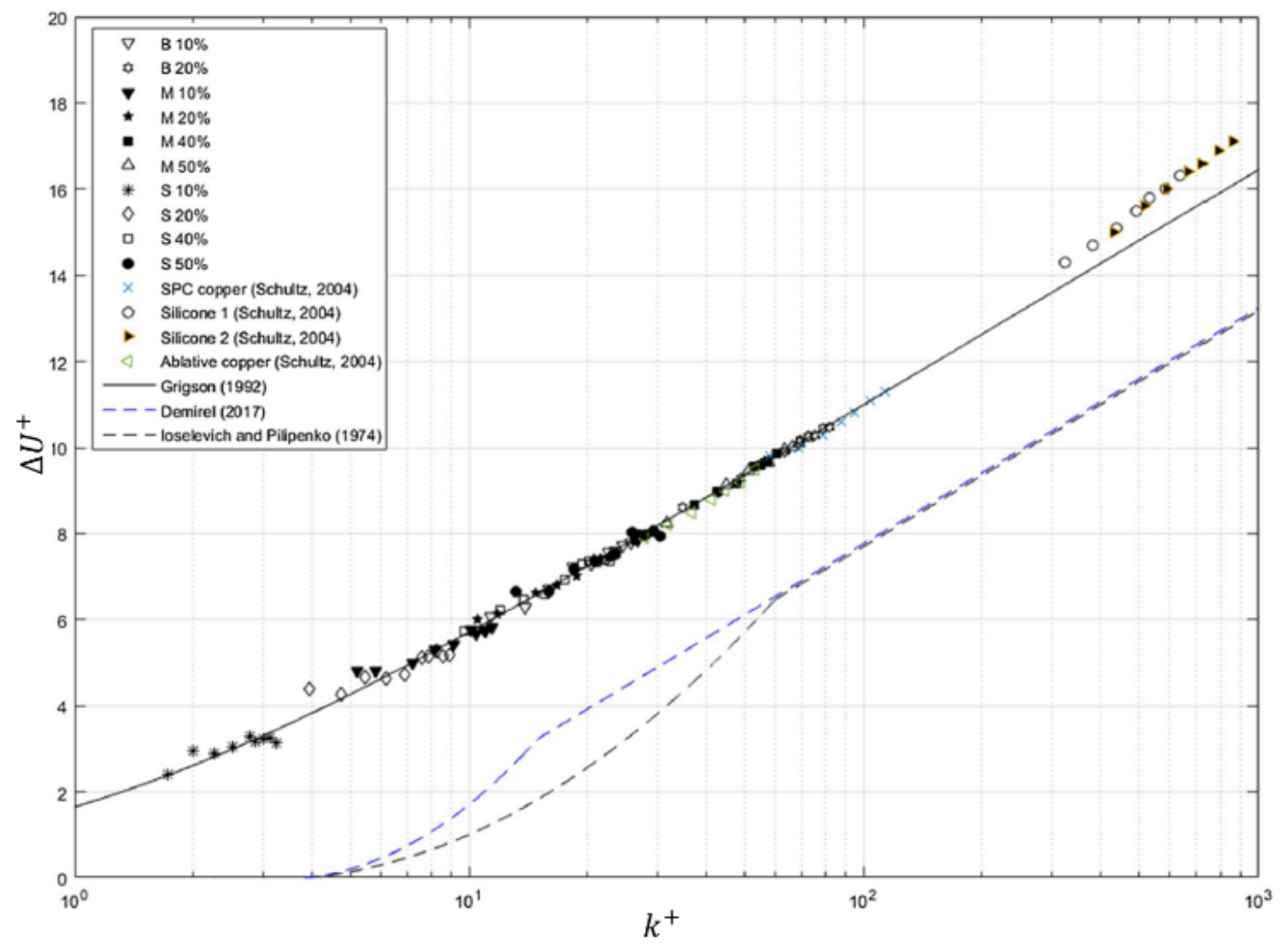

Figure 4 Roughness function for the fouling conditions, adapted from Demirel et al. [24]

\subsection{Mathematical formulation}

The proposed CFD model was developed based on the Reynolds-averaged Navier-Stokes (RANS) method using a commercial CFD software package, STAR-CCM+. The averaged continuity and momentum equations for incompressible flows may be given in tensor notation and Cartesian coordinates as in the following two equations [26].

$$
\begin{gathered}
\frac{\partial\left(\rho \bar{u}_{i}\right)}{\partial x_{i}}=0 \\
\frac{\partial\left(\rho \bar{u}_{i}\right)}{\partial t}+\frac{\partial}{\partial x_{j}}\left(\rho \bar{u}_{i} \bar{u}_{j}+\rho \overline{u_{\imath}^{\prime} u_{\jmath}^{\prime}}\right)=-\frac{\partial \bar{p}}{\partial x_{i}}+\frac{\partial \bar{\tau}_{i j}}{\partial x_{j}}
\end{gathered}
$$

in which, $\rho$ is density, $\bar{u}_{i}$ is the averaged velocity vector, $\rho \overline{u_{\imath}^{\prime} u_{\jmath}^{\prime}}$ is the Reynolds stress, $\bar{p}$ is the averaged pressure, $\bar{\tau}_{i j}$ is the mean viscous stress tensor components. This viscous stress for a Newtonian fluid can be expressed as

$$
\bar{\tau}_{i j}=\mu\left(\frac{\partial \bar{u}_{i}}{\partial x_{j}}+\frac{\partial \bar{u}_{j}}{\partial x_{i}}\right)
$$


where $\mu$ is the dynamic viscosity.

In the CFD solver, the computational domains were discretised and solved using a finite volume method. The second-order upwind convection scheme was used for the momentum equations. The flow equations were solved in a segregated manner. The continuity and momentum equations were linked with a predictor-corrector approach.

The shear stress transport (SST) $k-\omega$ turbulence model was used to predict the effects of turbulence, which combines the advantages of the $k-\omega$ and the $k-\varepsilon$ turbulence model. This model uses a $k-\omega$ formulation in the inner parts of the boundary layer and a $k-\varepsilon$ behaviour in the free-stream for a more accurate near-wall treatment with less sensitivity of inlet turbulence properties, which brings a better prediction in adverse pressure gradients and separating flow [27].

\subsection{HATT geometry and simulation conditions}

In this study, a full-scale CFD model of a typical three-bladed HATT was developed. The turbine model was designed and tested by Wang et al. [28] and Shi et al [36] and validated by a model-scale CFD study [29]. Table 2 and Figure 5 show the principal parameters and the geometry of the HATT.

The simulations were conducted in the smooth (clean) condition and 10 different fouling scenarios according to the barnacle sizes and coverages densities which can be found in Table 1. For each surface condition, simulations were conducted at the tip speed ratios, TSR, ranging 1-8. In order to vary the TSR values, the rotational speed $(\omega)$ was differed to match the corresponding TSR values, while the incoming velocity remains constant $\left(V_{\text {in }}=3.2 \mathrm{~m} / \mathrm{s}\right)$. The tip speed ratio, TSR was calculated as

$$
T S R=\frac{\omega R}{V_{\text {in }}}
$$

where $\omega, R$, and $V_{\text {in }}$ are the rotational speed $(\mathrm{rad} / \mathrm{s})$, blade radius of the turbine $(\mathrm{m})$ and the incoming velocity $(\mathrm{m} / \mathrm{s})$, respectively.

For each simulation case, the power coefficient, $C_{P}$, and the thrust coefficient, $C_{T}$, were calculated as 


$$
\begin{aligned}
C_{P} & =\frac{P}{\frac{1}{2} \rho A_{T} V_{i n}^{3}} \\
C_{T} & =\frac{T}{\frac{1}{2} \rho A_{T} V_{i n}^{2}}
\end{aligned}
$$

where $\omega, R$, and $V_{\text {in }}$ are the rotational speed $(\mathrm{rad} / \mathrm{s})$, blade radius of the turbine $(\mathrm{m})$ and the incoming velocity $(\mathrm{m} / \mathrm{s})$, respectively.

Table 2 Main parameters of the HATT, Shi et. al[35]

\begin{tabular}{ll}
\hline Diameter $(\mathrm{m})$ & 20 \\
Number of blades & 3 \\
Immersion of shaft $(\mathrm{m})$ & 20 \\
Rotation rate $(\mathrm{RPM})$ & 12 \\
Current speed $(\mathrm{m} / \mathrm{s})$ & 3.2 \\
\hline
\end{tabular}

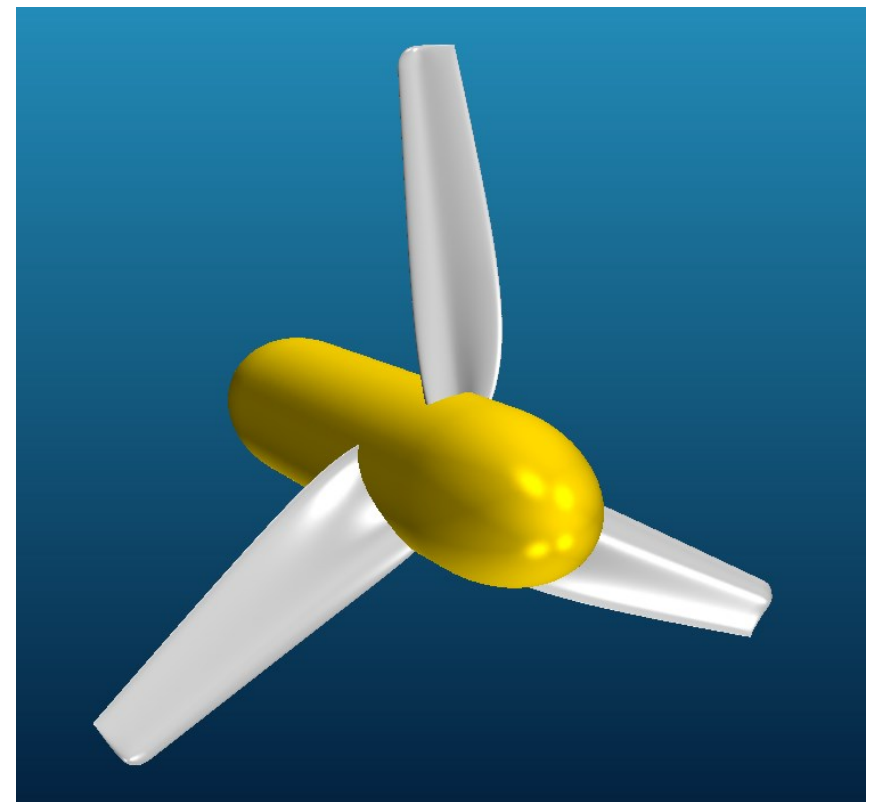

Figure 5 Geometry of the HATT

\subsection{Computational domain and boundary conditions}

Figure 6 depicts an overview of the computational domain with the selected boundary conditions in the CFD simulations. The computational domain consists of a stationary region (outer zone) and a rotating region (inner zone). The inlet, outlet and surrounding walls were placed to simulate the conditions of the cavitation tunnel experiment of Wang et al. [28]. The boundary conditions for the inlet and outlet were defined as a velocity inlet and a pressure 
outlet, while the slip-wall boundary conditions were used for the surrounding walls, as the boundary layer flow on the wall is assumed to be negligible for the performance of the turbine.

The Moving Reference Frame (MRF) approach was used to simulate the rotating turbine [30]. The MRF approach, also known as "Multiple Reference Frame" or "Frozen Rotor Approach", is a steady-state approximation. In this approach, the individual cell zones are assigned different translational and/or rotational motions and solved using the corresponding equations of the reference frames. For example, a rotating frame is used for the inner zone (yellow cylinder in Figure 6), a stationary frame is used for the outer zone. Since the MRF approach does not require complicated mesh motion and uses a steady-state solver for the flow field, it is simpler and computationally cheaper compared to other unsteady approaches (e.g. the Sliding Mesh). As proven by other studies [17, 31], the authors believe that the MRF method does not bring any significant difference in the results compared to other unsteady methods, as this study is not concerning about the transient behaviours.

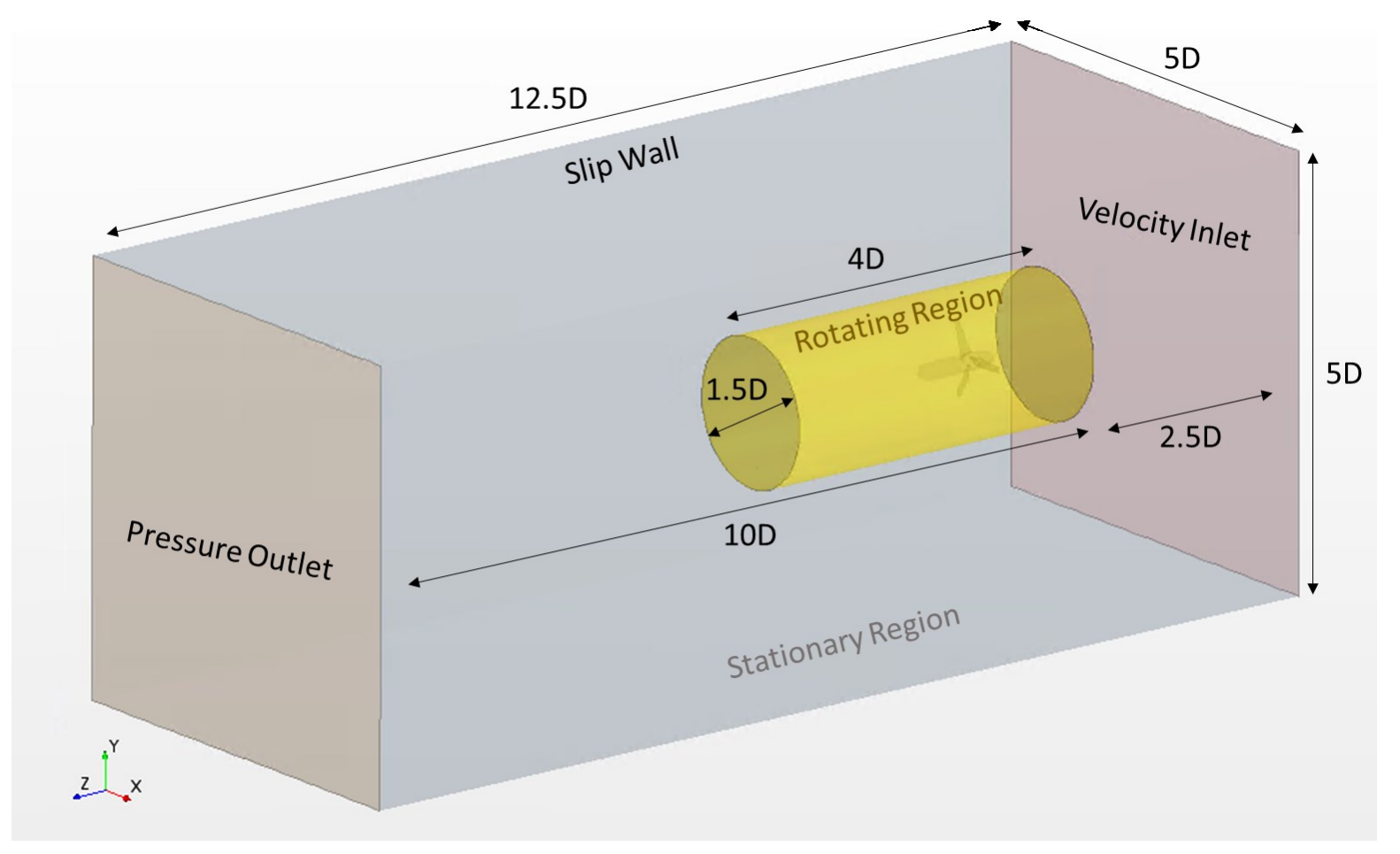

Figure 6 Domain and boundary conditions of the simulation model

\subsection{Mesh generation}

Mesh generation was performed using the built-in automated mesh tool of STAR-CCM+. Unstructured polyhedral meshes were used for the simulations, which enables to achieve accurate results with a less computational cost. Local refinements were made for finer grids in 
the critical regions, such as the region near the blades where the vortices and separations are expected to occur as shown in Figure 7.

The prism layer meshes were used for near-wall refinement, and the thickness of the first layer cell on the surfaces was chosen such that the $y^{+}$value is always higher than 30 and $k^{+}$, as suggested by Demirel et al. [14] and CD-Adapco [31].

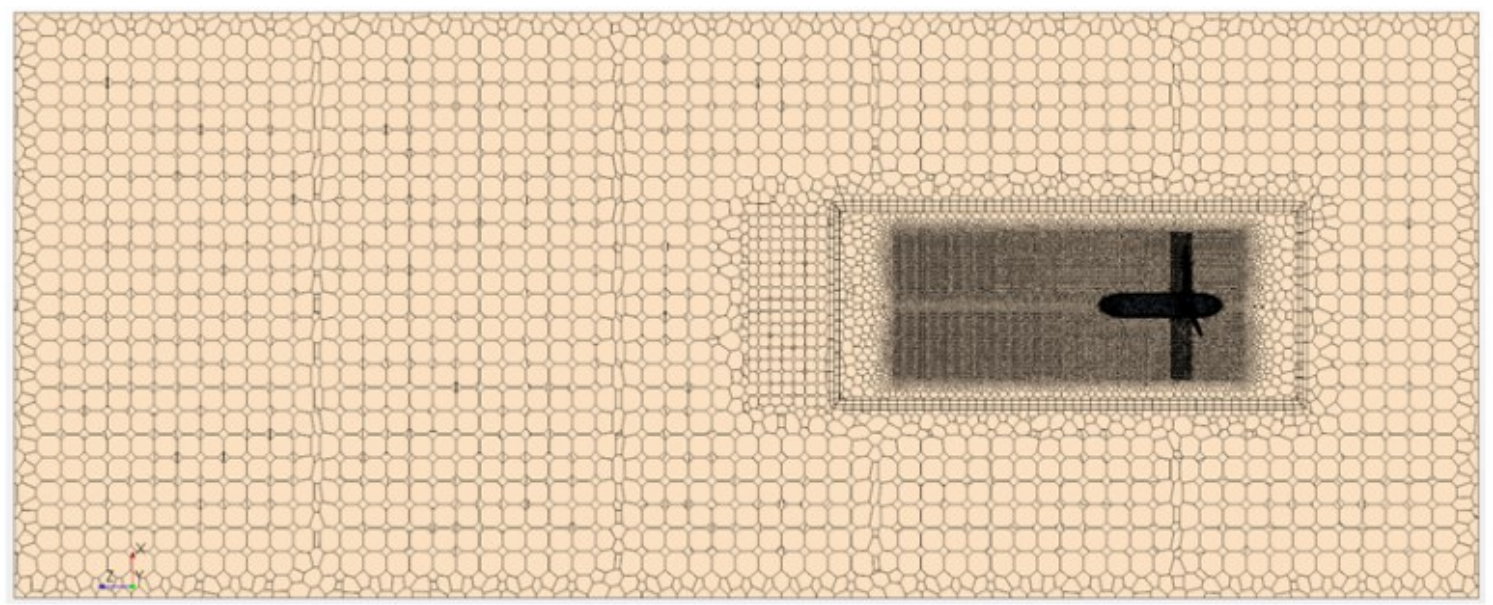

(a) Side view

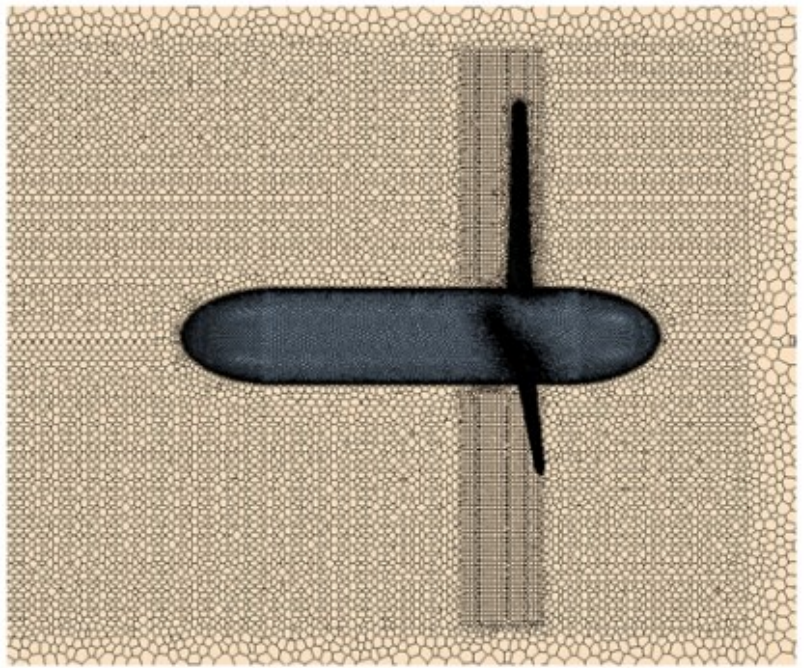

(b) Grid refinement near the blades

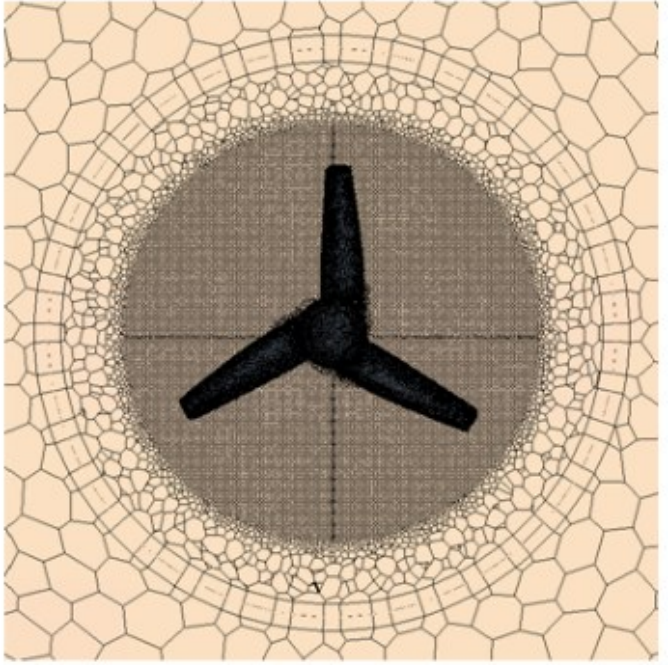

(c) Front view

Figure 7 Grid system of the simulation model 


\section{Results}

\subsection{Verification study}

A verification study was conducted to evaluate the numerical uncertainties of the CFD model and to determine a sufficient mesh spacing. The Grid Convergence Index (GCI) method based on the extrapolation method of Richardson [32] was used to estimate the order of accuracy of the simulation model.

According to Celik et al. [33] the apparent order of the method, $p_{a}$, is determined by

$$
\begin{gathered}
p_{a}=\frac{1}{\ln \left(r_{21}\right)}|\ln | \frac{\varepsilon_{32}}{\varepsilon_{21}}\left|+q\left(p_{a}\right)\right| \\
q\left(p_{a}\right)=\ln \left(\frac{r_{21}^{p_{a}}-s}{r_{32}^{p_{a}}-\mathrm{s}}\right) \\
s=\operatorname{sign}\left(\frac{\varepsilon_{32}}{\varepsilon_{21}}\right)
\end{gathered}
$$

where $r_{21}$ and $r_{32}$ are refinement factors given by $r_{21}=\sqrt[3]{N_{1} / N_{2}}$ for a spatial convergence study of a 3D model. $N$ denotes the cell number of the numerical domain. $\varepsilon_{32}=\phi_{3}-$ $\phi_{2}, \varepsilon_{21}=\phi_{2}-\phi_{1}$, and $\phi_{k}$ denote the key variables, e.g. $C_{P}$, or $C_{T}$ in this study.

The extrapolated value is calculated by

$$
\phi_{\text {ext }}^{21}=\frac{r_{21}^{p} \phi_{1}-\phi_{2}}{r_{21}^{p}-1}
$$

The approximate relative error, $e_{a}^{21}$, and extrapolated relative error, $e_{\text {ext }}^{21}$, are then obtained by

$$
\begin{gathered}
e_{a}^{21}=\left|\frac{\phi_{1}-\phi_{2}}{\phi_{1}}\right| \\
e_{\text {ext }}^{21}=\left|\frac{\phi_{\text {ext }}^{21}-\phi_{1}}{\phi_{\text {ext }}^{21}}\right|
\end{gathered}
$$

Finally, the fine-grid convergence index is found by

$$
G C I_{\text {fine }}^{21}=\frac{1.25 e_{a}^{21}}{r_{21}^{p}-1}
$$

Three different grid resolutions were generated for the grid convergence study, which are referred to as fine, medium and coarse meshes corresponding total cell numbers of $N_{1}, N_{2}$, and 
$N_{3}$. Table 3 indicates the required parameters for the numerical uncertainties arising from the spatial discretisation. The power coefficient, $C_{P}$ and thrust coefficient, $C_{T}$, at TSR $=4$, for the smooth case were used as the key variables. As shown in the table, the numerical uncertainties (GCI values) for $C_{P}$ and $C_{T}$ using the fine mesh are $0.24 \%$ and $0.04 \%$ respectively. For accurate prediction of the turbine performances, the fine mesh was used for the simulations.

Table 3 Discretisation error calculation for spatial convergence study

\begin{tabular}{lll}
\hline & \multicolumn{1}{c}{$C_{P}$} & \multicolumn{1}{c}{$C_{T}$} \\
\hline$N_{1}$ & $3,456,903$ & $3,456,903$ \\
$N_{2}$ & $2,434,588$ & $2,434,588$ \\
$N_{3}$ & $1,707,636$ & $1,707,636$ \\
$r_{21}$ & 1.19 & 1.19 \\
$r_{32}$ & 1.19 & 1.19 \\
$\phi_{1}$ (Fine) & $4.551 \mathrm{E}-01$ & $8.409 \mathrm{E}-01$ \\
$\phi_{2}$ (Medium) & $4.529 \mathrm{E}-01$ & $8.426 \mathrm{E}-01$ \\
$\phi_{3}$ (Course) & $4.448 \mathrm{E}-01$ & $8.319 \mathrm{E}-01$ \\
$\varepsilon_{32}$ & $-8.05 \mathrm{E}-03$ & $-1.07 \mathrm{E}-02$ \\
$\varepsilon_{21}$ & $-2.22 \mathrm{E}-03$ & $1.63 \mathrm{E}-03$ \\
$s$ & 1 & -1 \\
$e_{a}^{21}$ & $4.88 \mathrm{E}-03$ & $1.94 \mathrm{E}-03$ \\
$q$ & -0.02 & -0.02 \\
$p_{\mathrm{a}}$ & 7.23 & 10.64 \\
$\phi_{\text {ext }}^{21}$ & $4.560 \mathrm{E}-01$ & $8.407 \mathrm{E}-01$ \\
$e_{\text {ext }}^{21}$ & $-0.19 \%$ & $0.04 \%$ \\
$G C I_{\text {fine }}^{21}$ & $0.24 \%$ & $0.04 \%$ \\
\hline
\end{tabular}

\subsection{Validation study}

Figure 8 and 9 compare the $C_{P}$ and $C_{T}$ obtained from the CFD model in smooth condition and the experimental data of Wang et al. [28]. To examine the scale effect together, the coefficients obtained from the simulations of model-scale turbine $(\mathrm{D}=0.4 \mathrm{~m})$ are also included in the figure. As presented in the figure, a good agreement was achieved between the CFD and EFD results, except for the overpredicted $C_{P}$ and $C_{T}$ values at high TSRs ( $\left.6<\mathrm{TSR}\right)$, and also overpredicted $C_{P}$ around TSR $=2$. Considering that the model-scale CFD results show good agreement with the EFD data, this difference can be attributed to the scale effect due to the different Reynolds numbers. It is of note that the Reynold numbers, based on chord length at $0.7 \mathrm{R}$ and the relative flow velocity $\left(V_{R}=\sqrt{V_{A}^{2}+(0.7 \omega D)^{2}}\right)$ of the full-scale simulation and model-scale experiment are $1.0-6.8 \times 10^{7}$ and $1.3-8.5 \times 10^{5}$, respectively. 


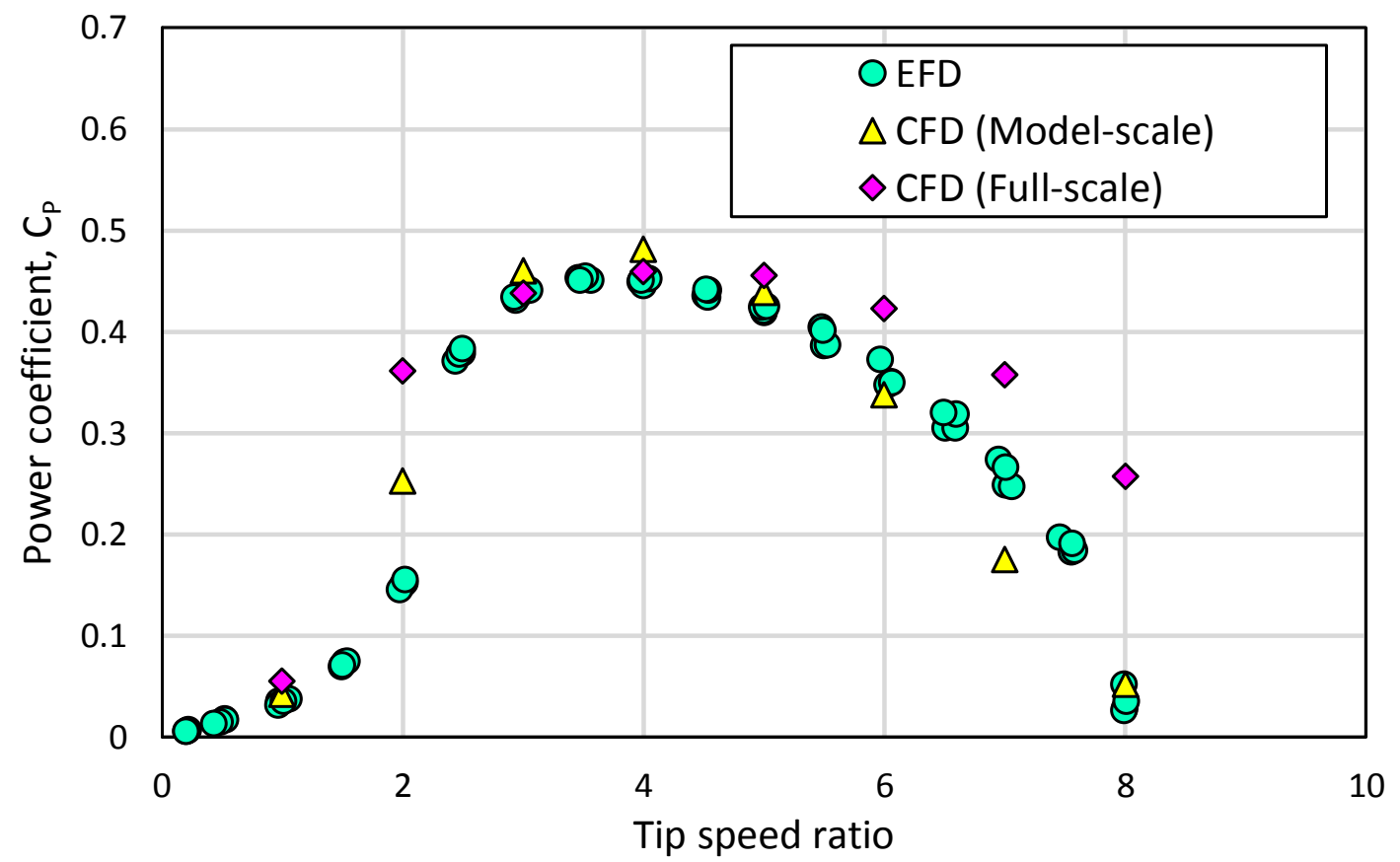

Figure 8 Comparison of the power coefficients obtained from the current CFD and EFD [28]

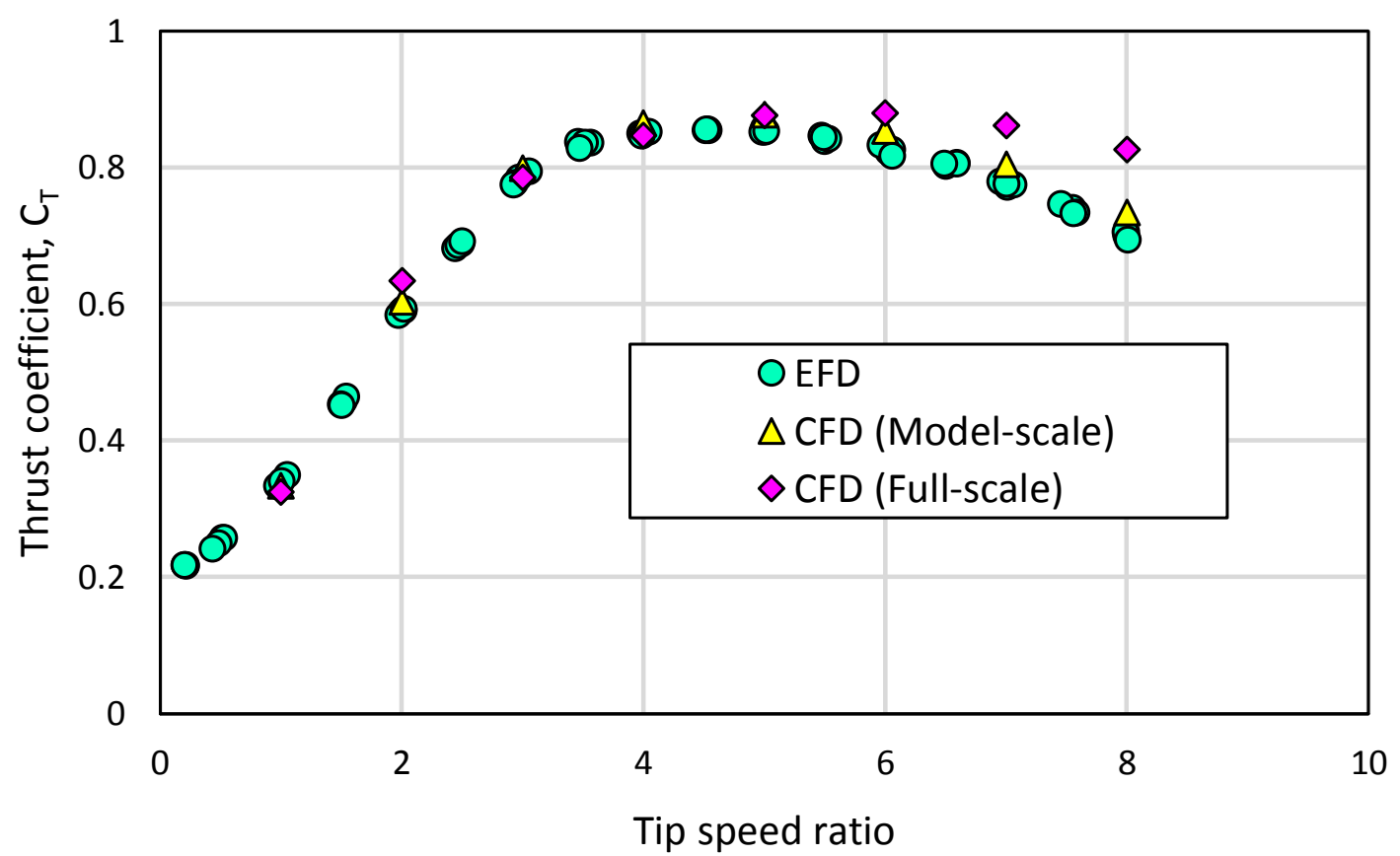

Figure 9 Comparison of the thrust coefficients obtained from the current CFD and EFD [28] 


\subsection{Roughness effect on the HATT}

\subsubsection{Power and thrust coefficient, $C_{P}$ and $C_{T}$}

In order to investigate the impact of biofouling on the performance of the HATT, CFD simulations of the full-scale turbine were conducted in different fouling scenarios, shown in Table 1, at TSR ranging from 1 to 8 .

Figure 10 demonstrates the impact of the surface fouling on the power coefficients, $C_{P}$ of the turbine at each TSR. The fouling cases were sorted in the order of fouling severity, which can be represented by the representative sand-grain roughness height, $k_{G}$, in Table 1 . As the table depicts, the $C_{P}$ values continuously decrease with increasing fouling rates. It was also noted that the reduction in $C_{P}$ becomes larger at higher TSR ranges. For example, the difference between the smooth and the most severe fouling condition (B20\%) is only $9 \%$ at $\mathrm{TSR}=3$, and it increases to $213 \%$ at $\mathrm{TSR}=8$, as can be seen in Table 4 .

Figure 11 illustrates the power coefficients, $C_{P}$ of the different fouling scenarios versus the tip speed ratios, TSR. The increased power losses at higher TSRs are clearly seen in the figure. This rapid decreases in $C_{P}$ values at higher TSRs result in narrower operable TSR range. For instance, the TSR range where $C_{P}$ is higher than 0.4 , for the most severe fouling condition $(\mathrm{B} 20 \%)$, is $3.0<\mathrm{TSR}<4.0$ and it is narrower than a fifth of the that of smooth case, $2.25<$ TSR $<7.4$.

Another interesting finding from the result is the change in the optimum TSR point where the highest $C_{P}$ is found. Table 5 shows the maximum $C_{P}$ values for the different fouling scenarios and the corresponding TSR values. The roughness effect of the surface fouling not only reduces the maximum $C_{P}$ value of each case but also moves the corresponding rotational speed to lower TSR regions. It is of note that even for the mildest fouling case, the reduction of the optimum TSR is $14.2 \%$. This finding suggests that the optimum TSR for the smooth condition is no longer valid once the surface is fouled and, hence, the surface condition should also be considered when the operating condition is planned, in order to achieve the maximum efficiency of tidal turbines.

Figure 11 compares the thrust coefficients, $C_{T}$ for the tidal turbine in the different fouling scenarios. Interestingly, it appeared that the surface roughness also decreases the $C_{T}$ values, which is desirable in terms of the survivability, apart from the drastic impact of biofouling on the $C_{P}$ values. 

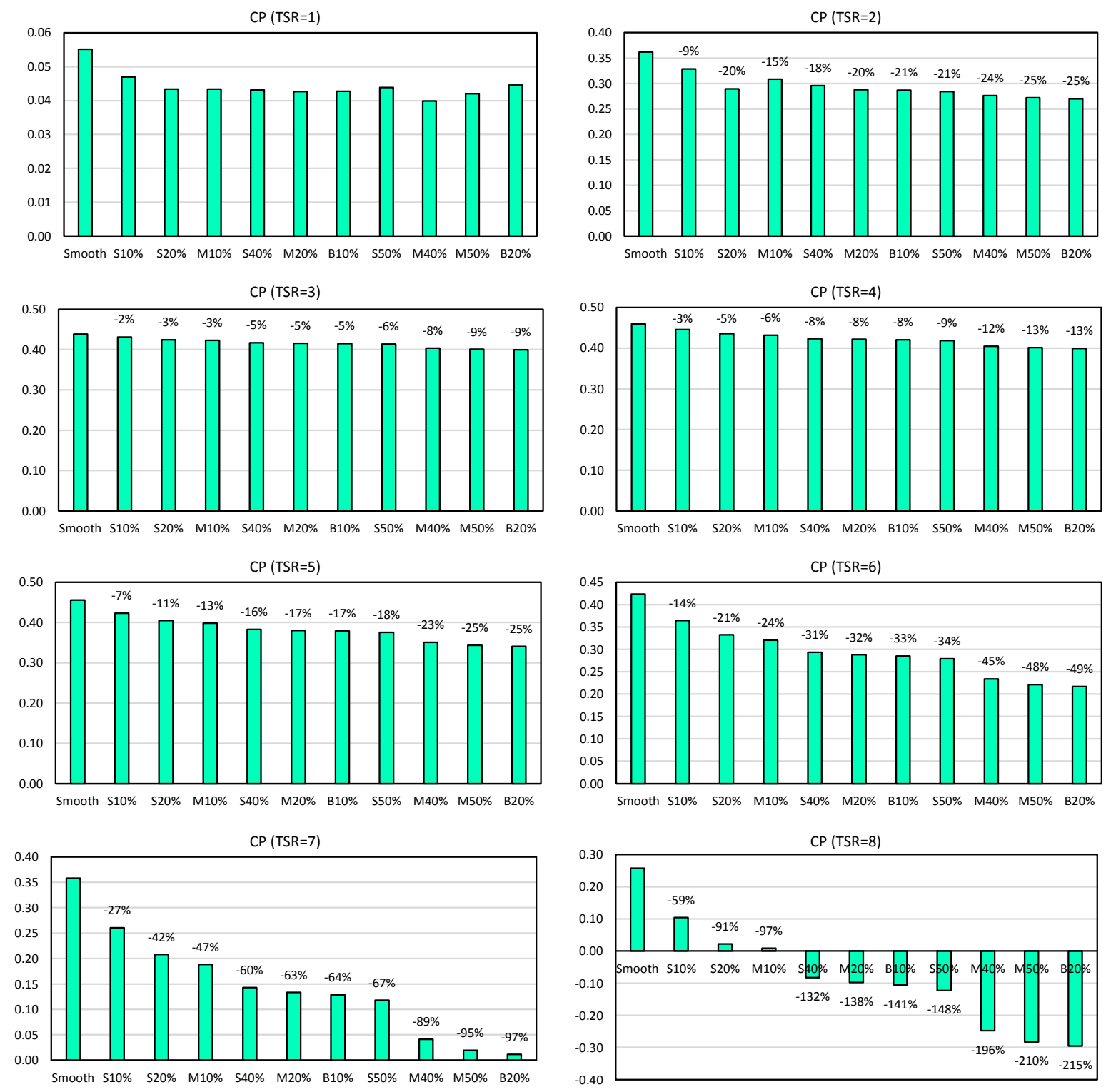

Figure 10 Comparisons of $C_{P}$ values in different fouling conditions at each TSR

Table 4 Comparisons of $C_{P}$ values in different fouling conditions

\begin{tabular}{|c|c|c|c|c|c|c|c|c|c|c|c|c|c|}
\hline & & $\mathrm{TSR}=3$ & & $\mathrm{TSR}=4$ & & $\mathrm{TSR}=5$ & & $\mathrm{TSR}=6$ & & $\mathrm{TSR}=7$ & & $\mathrm{TSR}=8$ & \\
\hline $\begin{array}{l}\text { Surface } \\
\text { condition }\end{array}$ & $k_{G}(\mu \mathrm{m})$ & $C_{P}$ & $\mathrm{D}(\%)$ & $C_{P}$ & $\mathrm{D}(\%)$ & $C_{P}$ & $\mathrm{D}(\%)$ & $C_{P}$ & $\mathrm{D}(\%)$ & $C_{P}$ & D (\%) & $C_{P}$ & $\mathrm{D}(\%)$ \\
\hline Smooth & 0 & 0.4382 & & 0.4592 & & 0.4554 & & 0.4233 & & 0.3579 & & 0.2572 & \\
\hline $\mathrm{S} 10 \%$ & 2 & 4313 & $-2 \%$ & 0.4456 & $-3 \%$ & 0.4230 & $-7 \%$ & 0.3644 & $-14 \%$ & 0.2604 & $-27 \%$ & 0.1043 & $-59 \%$ \\
\hline S $20 \%$ & 6 & 0.4241 & $-3 \%$ & 4354 & $-5 \%$ & 0.4049 & $-11 \%$ & 0.3323 & $-21 \%$ & 0.2079 & $-42 \%$ & 0.0220 & $-91 \%$ \\
\hline M 10\% & 84 & 0.4229 & $-3 \%$ & 0.4318 & $-6 \%$ & 0.3983 & $-13 \%$ & 0.3206 & $-24 \%$ & 0.1884 & $-47 \%$ & 0.0089 & $-97 \%$ \\
\hline S $40 \%$ & 149 & 0.4172 & $-5 \%$ & 0.4232 & $-8 \%$ & 0.3831 & $-16 \%$ & 0.2934 & $-31 \%$ & 0.1427 & $-60 \%$ & -0.0823 & $-132 \%$ \\
\hline M 20\% & 165 & 0.4159 & $-5 \%$ & 0.4215 & $-8 \%$ & 0.3801 & $-17 \%$ & 0.2879 & $-32 \%$ & 0.1335 & $-63 \%$ & -0.0974 & $-138 \%$ \\
\hline В $10 \%$ & 174 & 0.4153 & $-5 \%$ & 0.4206 & $-8 \%$ & 0.3785 & $-17 \%$ & 0.2850 & $-33 \%$ & 0.1286 & $-64 \%$ & -0.1054 & $-141 \%$ \\
\hline S 50\% & 194 & 0.4139 & $-6 \%$ & 0.4187 & $-9 \%$ & 0.3751 & $-18 \%$ & 0.2789 & $-34 \%$ & 0.1181 & $-67 \%$ & -0.1226 & $-148 \%$ \\
\hline M 40\% & 388 & 0.4038 & $-8 \%$ & 0.4048 & $-12 \%$ & 0.3505 & $-23 \%$ & 0.2340 & $-45 \%$ & 0.0411 & $-89 \%$ & -0.2478 & $-196 \%$ \\
\hline M 50\% & 460 & 0.4008 & $-9 \%$ & 0.4009 & $-13 \%$ & 0.3436 & $-25 \%$ & 0.2214 & $-48 \%$ & 0.0195 & $-95 \%$ & -0.2826 & $-210 \%$ \\
\hline В 20\% & 489 & 0.3996 & $-9 \%$ & 0.3994 & $-13 \%$ & 0.3410 & $-25 \%$ & 0.2168 & $-49 \%$ & 0.0115 & $-97 \%$ & -0.2956 & $-215 \%$ \\
\hline
\end{tabular}




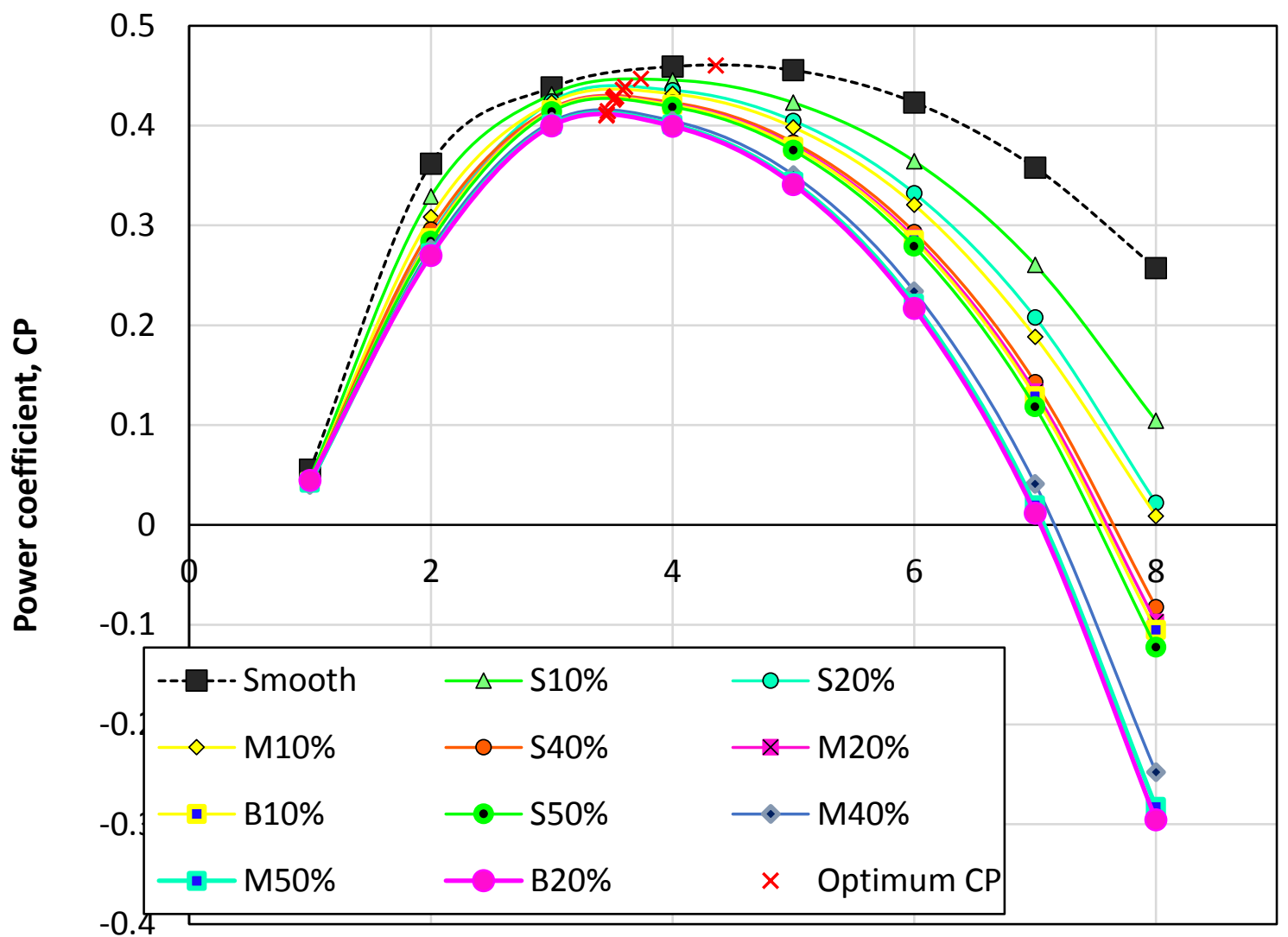

Tip speed ratio

Figure 11 Power coefficients calculated in different fouling scenarios

Table 5 Maximum $C_{P}$ value and corresponding TSR at each surface condition

\begin{tabular}{|c|c|c|c|c|c|}
\hline Surface condition & $k_{G}(\mu \mathrm{m})$ & Optimum $C_{P}$ & $\mathrm{D}(\%)$ & Corresponding TSR & $\mathrm{D}(\%)$ \\
\hline Smooth & 0 & 0.4604 & / & 4.3624 & / \\
\hline $\mathrm{S} 10 \%$ & 24 & 0.4468 & $-3.0 \%$ & 3.7587 & $-14.2 \%$ \\
\hline $\mathrm{S} 10 \%$ & 63 & 0.4391 & $-4.6 \%$ & 3.57777 & $-17.2 \%$ \\
\hline M10\% & 84 & 0.4358 & $-5.3 \%$ & 3.57 & $-17.6 \%$ \\
\hline $\mathrm{S} 40 \%$ & 149 & 0.4291 & $-6.8 \%$ & 3.5178 & $-18.9 \%$ \\
\hline $\mathrm{M} 20 \%$ & 165 & 0.4280 & $-7.0 \%$ & 3.5015 & $-19.2 \%$ \\
\hline B10\% & 174 & 0.4273 & $-7.2 \%$ & 3.4972 & $-19.3 \%$ \\
\hline $\mathrm{S} 50 \%$ & 194 & 0.4258 & $-7.5 \%$ & 3.4892 & $-19.5 \%$ \\
\hline M40\% & 388 & 0.4144 & $-10.0 \%$ & 3.4537 & $-20.5 \%$ \\
\hline M50\% & 460 & 0.4113 & $-10.7 \%$ & 3.4438 & $-20.7 \%$ \\
\hline B20\% & 489 & 0.4100 & $-10.9 \%$ & 3.4422 & $-20.8 \%$ \\
\hline
\end{tabular}




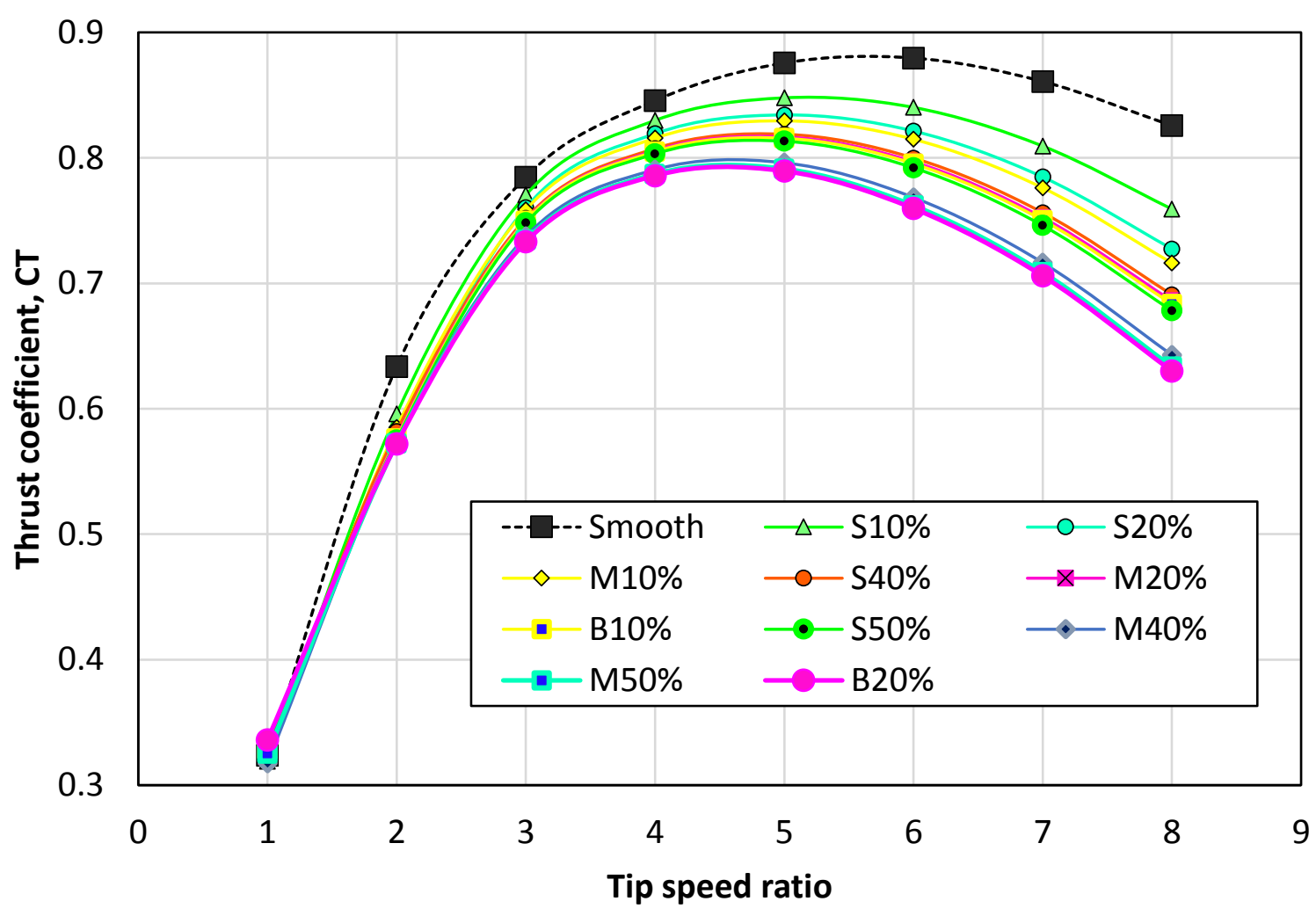

Figure 12 Thrust coefficients calculated in different fouling scenarios

\subsubsection{Contribution of shear and pressure torque components}

In order to investigate the rationale behind the increasing power loss due to the surface fouling at higher TSR regions, the components of the torque acting on the turbine were divided into shear and pressure components. Figure 13 illustrates the contributions of the pressure and shear components in the torque acting on the tidal turbine, in smooth condition and the most severe fouling (B20\%) condition. As can be seen in the figure, the shear torques are acting on the negative direction of the turbine, and they increase with the TSRs. The fouled case has more than twice larger magnitudes of shear torques that those of smooth case over the TSR ranges. It can be deduced that the increased surface roughness due to the surface fouling results in increased skin friction and hence increases shear torque, which causes the efficiency loss.

Figure 13 also depicts that, for both surface conditions, the pressure components of torque decreases with TSRs, but the rate of decrease for the fouled case is much higher than that for the smooth case. This accelerated decrease can be seen as a cause of the rapid loss in, $C_{P}$, in conjunction with the increased shear torque due to the surface fouling. 


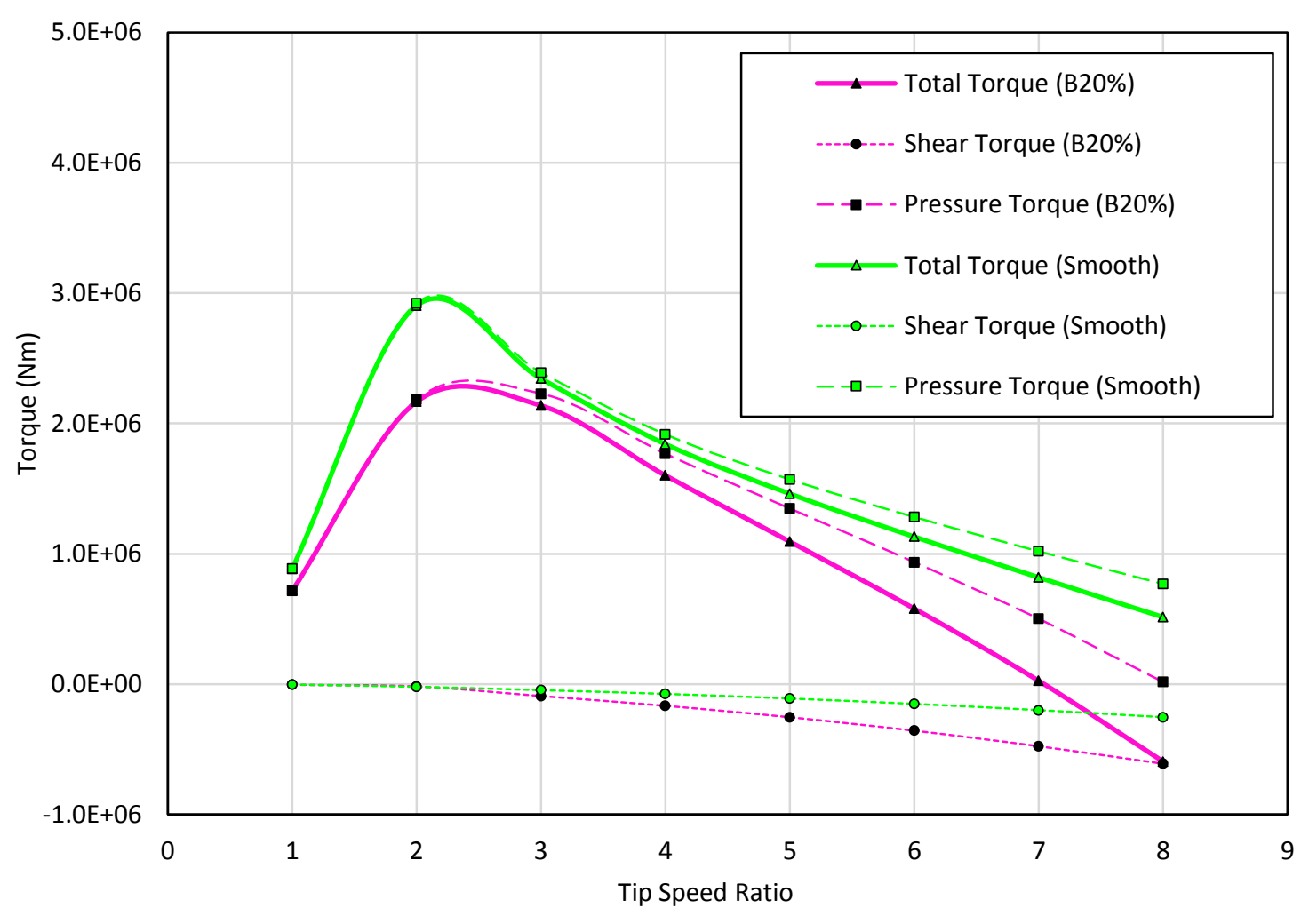

Figure 13 Contribution of the torque coefficient components

\subsubsection{Surface pressure}

Figure 14 and 15 compares the surface pressure on the turbine in the smooth and fouled (B20\%) surface conditions. The pressure was nondimensionalised by dividing it by the dynamic pressure, $1 / 2 \rho V_{i n}^{2}$. As can be seen in the figure, the fouled case has lower surface pressure on the blade in the face side and higher pressure in the backside. This observation is in agreement with the decreased pressure torque due to surface fouling, which can be found in Figure 13. 
(a) Smooth

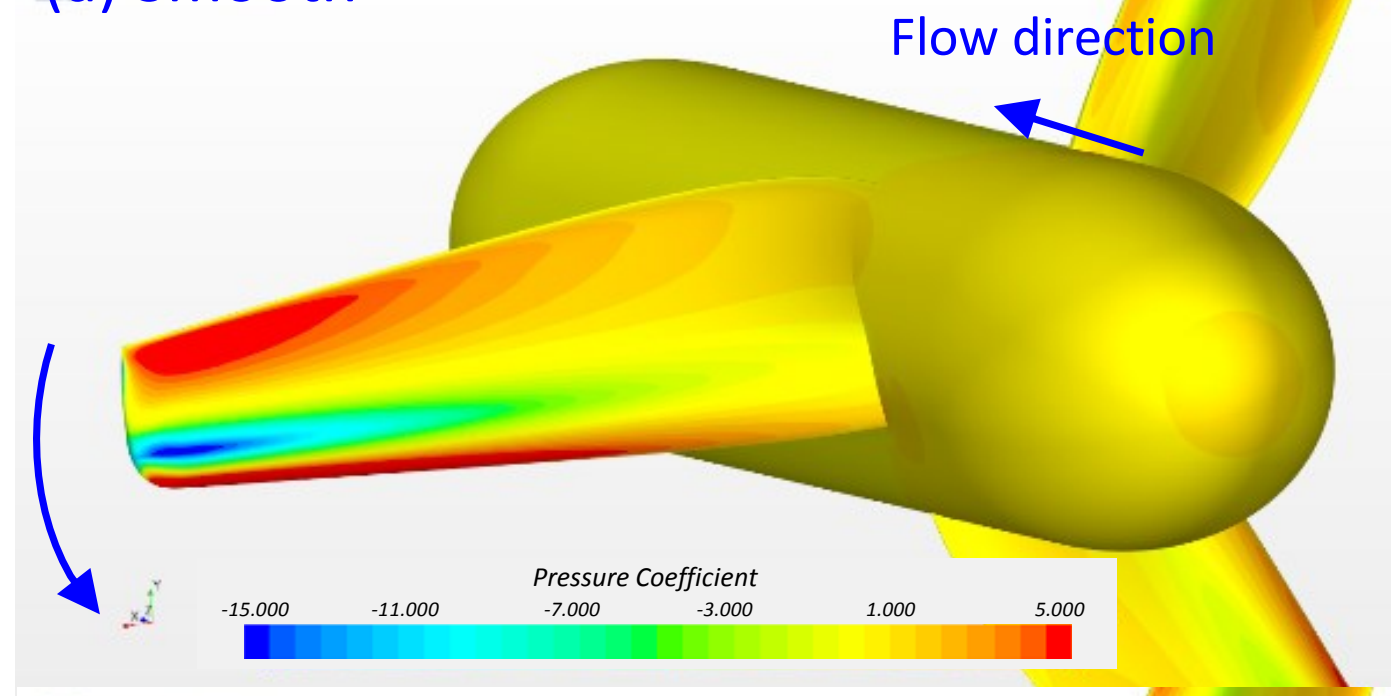

(b) $\mathrm{B} 20 \%$

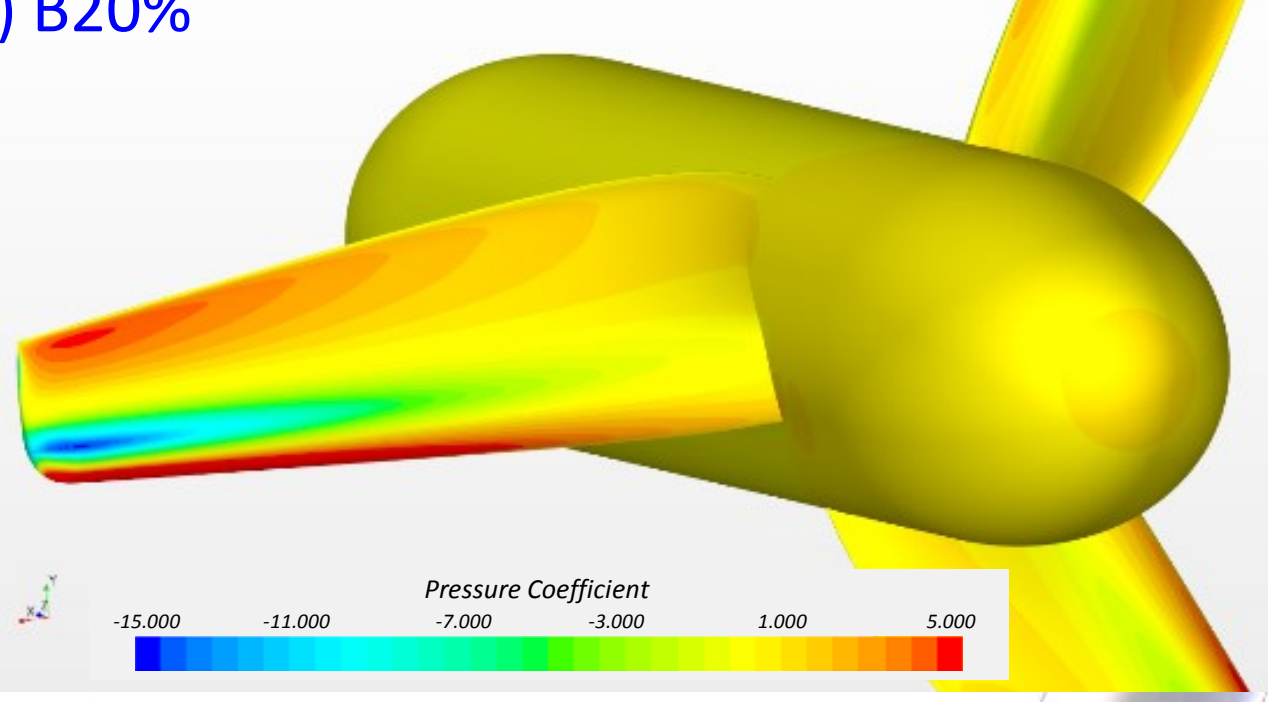

(c) Difference (Smooth-B20\%)

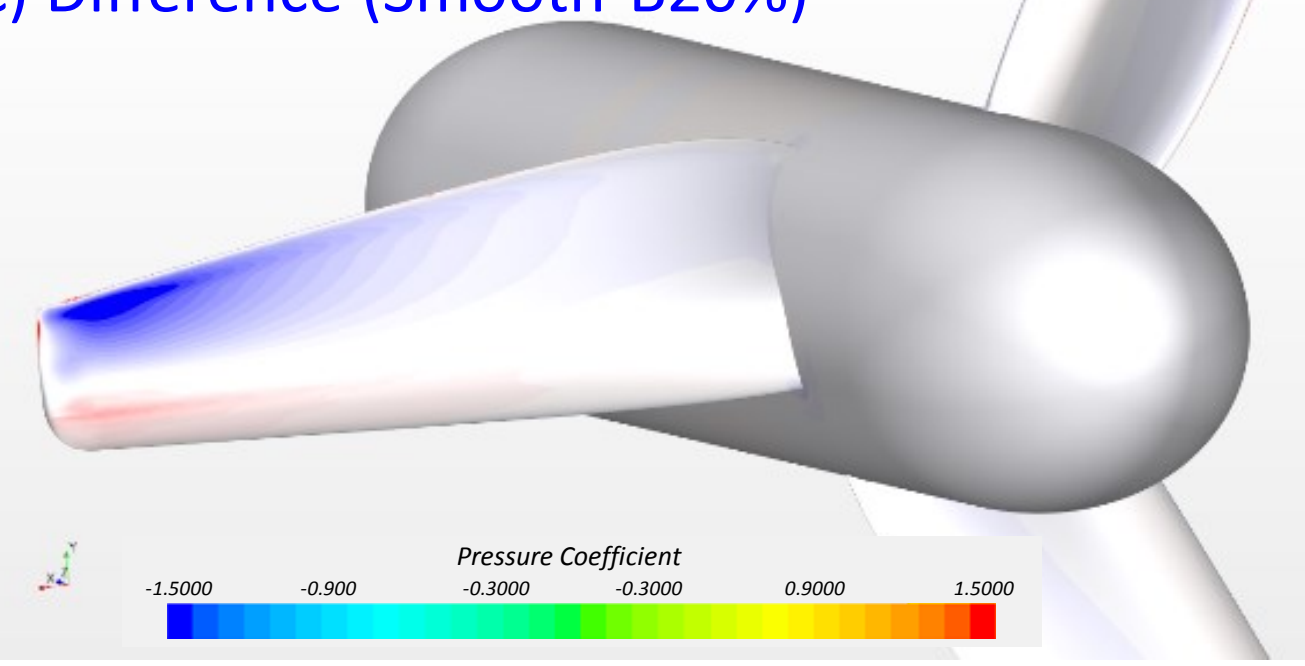

Figure 14 Pressure distribution on the turbine surface at $T S R=4$ (face-side) 


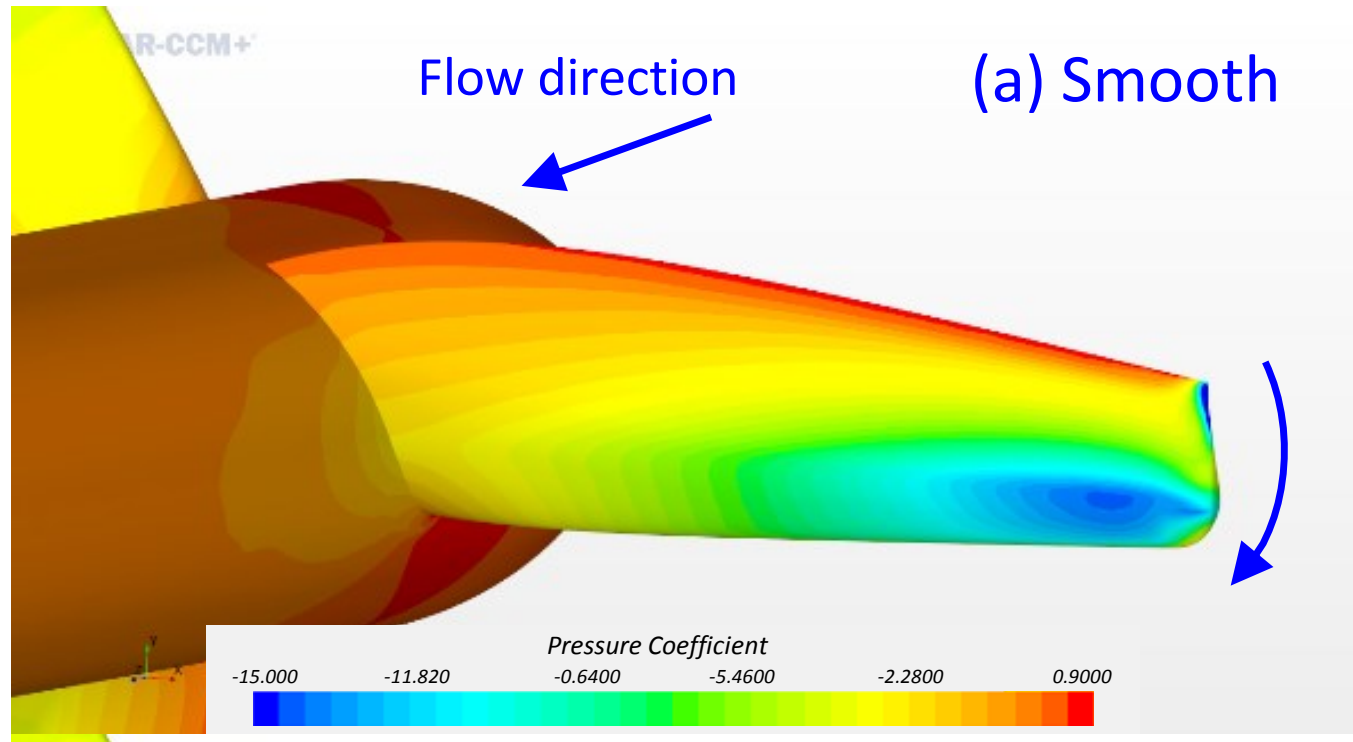

(b) $\mathrm{B} 20 \%$

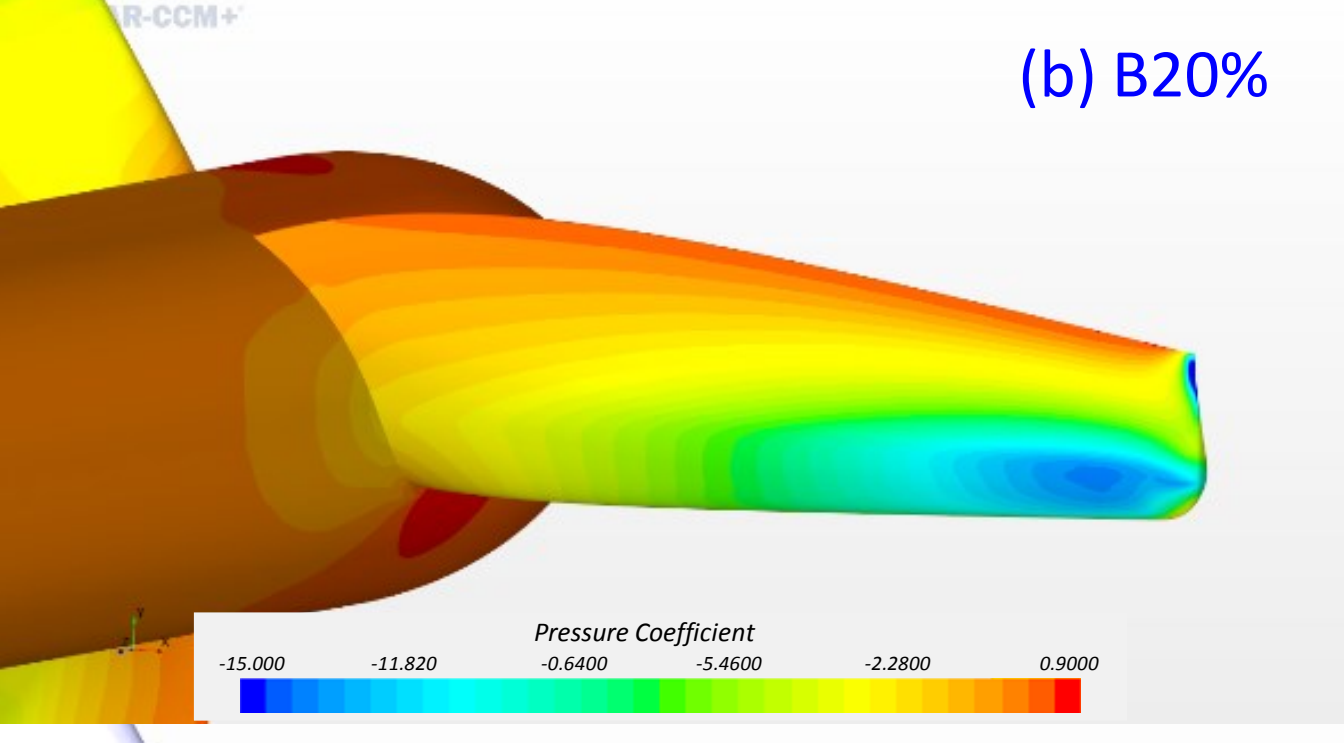

(c) Difference (Smooth-B20\%)

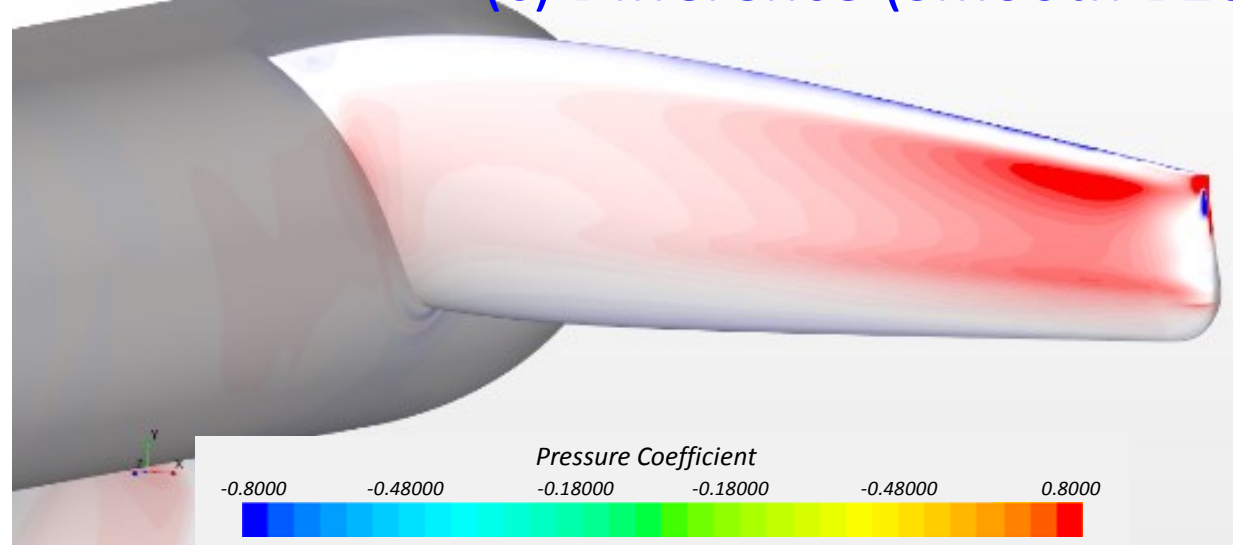

Figure 15 Pressure distribution on the turbine surface at TSR=4 (back-side) 


\subsubsection{Wall shear stress}

Figure 16 illustrates the normalised wall shear stress magnitude on the turbine surface in the smooth and fouled (B20\%) surface scenario at $\mathrm{TSR}=4$. The wall shear stress was nondimensionalised by dividing it by the dynamic pressure, $1 / 2 \rho V^{2}$. As can be seen in the figure, significant increases in the wall shear stress were observed due to the surface fouling. The wall shear stress values for the fouled case were observed to be more than doubled due to the increased surface roughness, which is in accordance with the increased shear torque components observed in Figure 13.

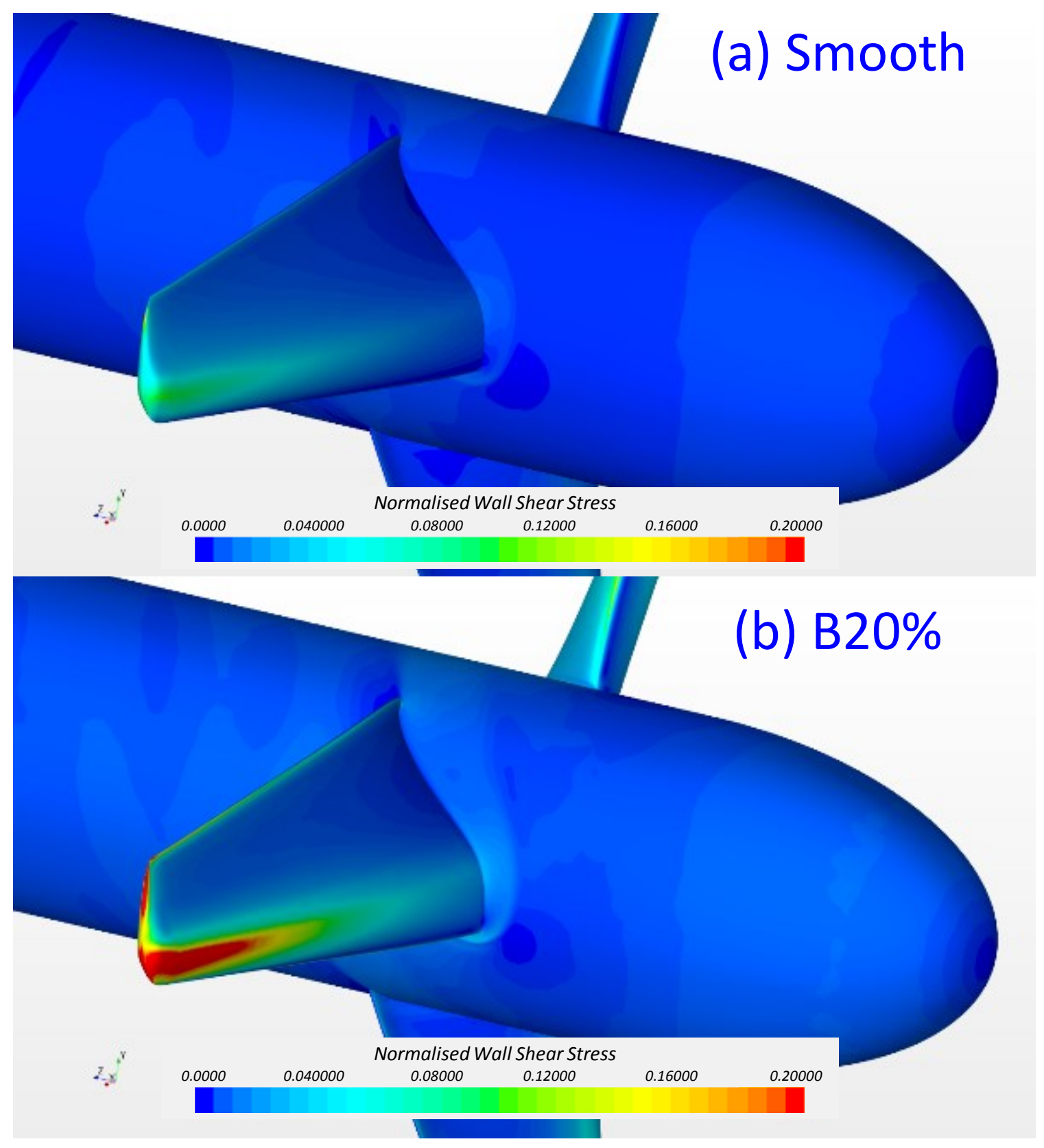

Figure 16 Shear stress distribution on the turbine surface, at $T S R=4$ 


\section{Concluding remarks}

A CFD model has been proposed for investigating the effect of biofouling on the performance of HATT. To represent the surface roughness of different fouling conditions, a previouslydeveloped modified wall-function approach was used to approximate the roughness effects of barnacles of varying sizes and coverage densities. The following concluding remarks can be drawn:

1. A verification study was carried out to assess the numerical uncertainties of the proposed CFD model and to determine sufficient grid-spacings. The numerical uncertainties for $C_{P}$ and $C_{T}$ were estimated to be $0.24 \%$ and $0.04 \%$, respectively. As a validation study, $C_{P}$ and $C_{T}$ curves obtained from the CFD simulations were compared with the experimental data [28] and showed reasonable agreements.

2. Fully nonlinear RANS simulations of the full-scale HATT were performed in different fouling conditions at a range of tip speed ratios, to investigate the impact of barnacle fouling on the tidal turbine performance. The simulation results showed a drastic impact of surface fouling on the efficiency of the tidal turbine. The power coefficients, $C_{P}$, showed a decreasing trend with increasing fouling rates, and larger decreases were found at higher TSR regions.

3. This rapid reduction in $C_{P}$ appeared to cause narrower operable TSR ranges. In the most severe fouling condition (B20\%), the operable TSR range $\left(C_{P}>0.4\right)$ was found to be narrower than a fifth of that for the smooth condition.

4. The torque acting on the turbine was divided into the shear and pressure components, and it was found that the increased surface roughness due to the surface fouling causes in decreased torque and increased shear torque, resulting in reduced power coefficients. The surface pressure and wall shear stress were also examined, and the reduced pressure difference between face and backside of the turbine and significantly increased wall shear stress were observed, which are in accordance with the reduced pressure torque and increased shear torque.

The most interesting finding from the result is that the optimum TSR point, where the highest $C_{P}$ can be achieved, moved to lower TSR regions due to the surface fouling. This finding suggests if the operation strategy, the operation TSR, can be changed with regarding to the fouling condition, the fouling effect on the tidal turbine efficiency can be mitigated so that the maintainence schedule can be extended to lower the OPEX and hence the LCOE. In a nutshell, 
to operate a heavily fouled turbine, slowing it down is the mitigation measures to safeguard the turbine's efficiency to maxmise the power output.

\section{Acknowledgements}

It should be noted that the results were obtained using the ARCHIE-WeSt High Performance Computer (www.archie-west.ac.uk) based at the University of Strathclyde. The research is partially sponsored by H2020 project, ELEMENT (Ref: 815180). 


\section{References}

1. Charlier, R. H. (2003). A “sleeper" awakes: tidal current power. Renewable and Sustainable Energy Reviews, 7(6), 515-529. doi: https://doi.org/10.1016/S1364$\underline{0321(03) 00079-0}$

2. Li, D., Wang, S., \& Yuan, P. (2010). An overview of development of tidal current in China: Energy resource, conversion technology and opportunities. Renewable and Sustainable Energy Reviews, 14(9), 2896-2905. doi: https://doi.org/10.1016/j.rser.2010.06.001

3. Pelc, R., \& Fujita, R. M. (2002). Rnewable enrgy from the ocean. Marine Policy, 26, 471-479.

4. Lewis, J. (1998). Marine biofouling and its prevention on underwater surfaces (Vol. 22).

5. Gehrke, T., \& Sand, W. (2003). Interactions Between Microorganisms and Physiochemical Factors Cause MIC of Steel Pilings in Harbors (ALWC). Paper presented at the CORROSION 2003, San Diego, California. https://doi.org/

6. Titah-Benbouzid, H., \& Benbouzid, M. (2015, 2015-09-06). Marine Renewable Energy Converters and Biofouling: A Review on Impacts and Prevention. Paper presented at the EWTEC 2015, Nantes, France.

7. Fraenkel, P. L. (2002). Power from marine currents. Proceedings of the Institution of Mechanical Engineers, Part A: Journal of Power and Energy, 216(1), 1-14. doi: $10.1243 / 095765002760024782$

8. Ng, K.-W., Lam, W.-H., \& Ng, K.-C. (2013). 2002-2012: 10 Years of Research Progress in Horizontal-Axis Marine Current Turbines. Energies, 6(3), 1497.

9. Orme, J. A. C., Masters, I., \& Griffiths, R. T. (2001). Investigation of the effect of biofouling on the efficiency of the marine current turbines. Paper presented at the the Marine Renewable Energy Conference, Newcastle Upon Tyne, UK.

10. Batten, W., Bahaj, A., Molland, A. F., \& Chaplin, J. R. (2008). The Prediction of the Hydrodynamic Performance of Marine Current Turbines (Vol. 33).

11. Walker, J., Flack, K., Lust, E., Schultz, M., \& Luznik, L. (2014). Experimental and numerical studies of blade roughness and fouling on marine current turbine performance (Vol. 66).

12. Franzini, J. (1997). Fluid Mechanics with Engineering Applications: 9th edition (9 ed.). New York: McGraw-Hill. 
13. Demirel, Y. K., Khorasanchi, M., Turan, O., Incecik, A., \& Schultz, M. P. (2014). A CFD model for the frictional resistance prediction of antifouling coatings. Ocean Engineering, 89, 21-31. doi: https://doi.org/10.1016/j.oceaneng.2014.07.017

14. Demirel, Y. K., Turan, O., \& Incecik, A. (2017). Predicting the effect of biofouling on ship resistance using CFD. Applied Ocean Research, 62, 100-118. doi: https://doi.org/10.1016/j.apor.2016.12.003

15. Farkas, A., Degiuli, N., \& Martić, I. (2018). Towards the prediction of the effect of biofilm on the ship resistance using CFD. Ocean Engineering, 167, 169-186. doi:https://doi.org/10.1016/j.oceaneng.2018.08.055

16. Song, S., Demirel, Y. K., \& Mehmet, A. (2019). An Investigation into the Effect of Biofouling on the Ship Hydrodynamic Characteristics using CFD. Ocean Engineering.

17. Owen, D., Demirel, Y. K., Oguz, E., Tezdogan, T., \& Incecik, A. (2018). Investigating the effect of biofouling on propeller characteristics using CFD. Ocean Engineering. doi: https://doi.org/10.1016/j.oceaneng.2018.01.087

18. Song, S., Demirel, Y. K., \& Atlar, M. (2020). Propeller Performance Penalty of Biofouling: Computational Fluid Dynamics Prediction. Journal of Offshore Mechanics and Arctic Engineering, 142(6). doi:10.1115/1.4047201

19. Song, S., Demirel, Y. K., \& Atlar, M. (2020). Penalty of hull and propeller fouling on ship self-propulsion performance. Applied Ocean Research, 94, 102006. doi:https://doi.org/10.1016/j.apor.2019.102006

20. Song, S., Demirel, Y. K., Atlar, M., Dai, S., Day, S., \& Turan, O. (2019). Validation of the CFD approach for modelling roughness effect on ship resistance. Paper presented at the Sixth International Conference on Advanced Model Measurement Technology for The Maritime Industry (AMT'19), Rome, Italy.

21. Song, S., Demirel, Y. K., Atlar, M., Dai, S., Day, S., \& Turan, O. (2020). Validation of the CFD approach for modelling roughness effect on ship resistance. Ocean Engineering, 200, 107029. doi:https://doi.org/10.1016/j.oceaneng.2020.107029

22. Song, S., Dai, S., Demirel, Y. K., Atlar, M., Day, S., \& Turan, O. (2020). Experimental and theoretical study of the effect of hull roughness on ship resistance. Journal of Ship Research (under review)

23. Clauser, F. H. (1954). Turbulent Boundary Layers in Adverse Pressure Gradients. Journal of the Aeronautical Sciences, 21(2), 91-108. doi: 10.2514/8.2938 
24. Demirel, Y. K., Uzun, D., Zhang, Y., Fang, H.-C., Day, A. H., \& Turan, O. (2017). Effect of barnacle fouling on ship resistance and powering. Biofouling, 33(10), 819834. doi: 10.1080/08927014.2017.1373279

25. Grigson, C. (1992). Drag losses of new ships caused by hull finish. Journal of Ship Research, 36, 182-196.

26. Ferziger, J. H., \& Peric, M. (2002). Computational Methods for Fluid Dynamics: Springer-Verlag Berlin Heidelberg.

27. Menter, F. R. (1994). Two-Equation Eddy-Viscosity Turbulence Models for Engineering Applications. AIAA Journal, 32(8), 1598-1605.

28. Wang, D., Atlar, M., \& Sampson, R. (2007). An experimental investigation on cavitation, noise, and slipstream characteristics of ocean stream turbines. Proceedings of the Institution of Mechanical Engineers, Part A: Journal of Power and Energy, 221(2), 219-231. doi: 10.1243/09576509JPE310

29. Shi, W., Wang, D., Atlar, M., \& Seo, K. C. (2013). Flow separation impacts on the hydrodynamic performance analysis of a marine current turbine using CFD. Proceedings of the Institution of Mechanical Engineers, Part A: Journal of Power and Energy, 227(8), 833-846. doi: 10.1177/0957650913499749

30. Luo, J. Y., Issa, R. I., \& Gosman, A. D. (1994). Prediction of impeller induced flows in mixing vessels using multiple frames of reference. Paper presented at the 8th European conference on mixing; INSTITUTION OF CHEMICAL ENGINEERS SYMPOSIUM SERIES, Cambridge.

31. Mizzi, K., Demirel, Y. K., Banks, C., Turan, O., Kaklis, P., \& Atlar, M. (2017). Design optimisation of Propeller Boss Cap Fins for enhanced propeller performance. Applied Ocean Research, 62, 210-222. doi: https://doi.org/10.1016/j.apor.2016.12.006

32. CD-Adapco. (2017). STAR-CCM+ user guide, version 12.06.

33. Richardson, L. F. (1910). The approximate arithmetical solution by finite differences of physical problems involving differential equations, with an application to the stresses in a masonry dam. Transcations of the Royal Society of London. Series A, 210, 307357.

34. Celik, I. B., Ghia, U., Roache, P. J., Freitas, C. J., Coleman, H., \& Raad, P. E. (2008). Procedure for Estimation and Reporting of Uncertainty Due to Discretization in CFD Applications. Journal of Fluids Engineering, 130(7), 078001-078001-078004. doi: $10.1115 / 1.2960953$ 
35. Shi, W., M. Atlar, R. Rosli, B. Aktas and R. Norman (2016). "Cavitation observations and noise measurements of horizontal axis tidal turbines with biomimetic blade leading-edge designs." Ocean Engineering 121: 143-155.

36. Shi, W., R. Rosli, M. Atlar, R. Norman, D. Wang and W. Yang (2016). "Hydrodynamic performance evaluation of a tidal turbine with leading-edge tubercles." Ocean Engineering 117: 246-253. 